\title{
Carcinoma of the Liver in Children and Adolescents
}

\author{
Consolato M. Sergi \\ Departments of Pediatrics, Laboratory Medicine and Pathology, Stollery Children's \\ Hospital, University of Alberta, Edmonton, AB, Canada.
}

Author for Correspondence: Consolato M. Sergi, Departments of Pediatrics, Laboratory Medicine and Pathology, Stollery Children's Hospital, University of Alberta, Edmonton, AB, Canada. Email: sergi@ualberta.ca

Doi: https://doi.org/10.36255/exonpublications.livercancer.2021.ch1

\begin{abstract}
Liver cancer, predominantly hepatocellular carcinoma, is the second most common cause of cancer-related death in adults. Although infrequent in children, hepatocellular carcinoma is a terrifying diagnosis. Rising levels of obesity and obesity-associated lipid metabolic reprogramming of hepatocytes are increasing the prevalence of lipid-rich hepatocellular carcinoma in young adults. Most pediatric liver cancers occur in otherwise healthy liver, with some exceptions such as progressive familial intrahepatic cholestasis, hereditary tyrosinemia, alpha-1-antitrypsin deficiency, and genetic hemochromatosis. In the last decade, although aggressive multidisciplinary treatments including surgical resection and chemotherapy have remarkably improved patient outcomes in terms of decreased recurrence rate and increased overall survival rate, in children with unresectable liver cancer, the 5-year survival rate is still less than $20 \%$. This chapter provides an overview of malignant epithelial tumors of the liver in children and adolescents. Hepatocellular carcinoma, lipid-rich hepatocellular carcinoma, fibrolamellar carcinoma, and cholangiocellular carcinoma are discussed.
\end{abstract}

Keywords: cholangiocarcinoma; fibrolamellar carcinoma; hepatocellular carcinoma; lipid-rich hepatocellular carcinoma; liver tumor in children

In: Liver Cancer. Sergi CM. (Editor). Exon Publications, Brisbane, Australia. ISBN: 978-0-6450017-2-3; Doi: https://doi.org/10.36255/exonpublications.livercancer.2021

Copyright: The Authors.

License: This open access article is licenced under Creative Commons Attribution-NonCommercial 4.0 International (CC BY-NC 4.0) https://creativecommons.org/licenses/by-nc/4.0/ 


\section{INTRODUCTION}

Liver tumors in children and adolescents are catastrophic events. While most occur in otherwise healthy liver, they may be associated with congenital anomalies, genetic syndromes or metabolic conditions. Two significant entities are hepatoblastoma (HBL) and liver carcinoma/hepatocellular carcinoma (HCC). Both neoplasms account for $0.5-1.5 \%$ of all childhood neoplasms (1) and $4 \%$ of all pediatric orthotopic liver transplantations (OLT). HBL accounts for $67-80 \%$ of all pediatric liver cancers worldwide, while 20-33\% are HCC. Prevalence of HCC is geographically and demographically dependent and is associated with the prevalence of Hepatitis B in the population (1). Differential diagnosis can be genuinely challenging considering the number of variants and subtypes that have been delineated over the last decade. Known predisposing factors for HCC in childhood and youth are alpha-1-antitrypsin deficiency, hereditary tyrosinemia, genetic hemochromatosis, Wilson's disease, acute intermittent porphyria, progressive familial intrahepatic cholestasis type 2, mitochondrial ETC disorders, glycogen storages diseases, and transaldolase deficiency. Several neoplastic conditions must also be considered in the differential diagnosis of HCC, including epithelioid hemangioendothelioma of the liver, hemangiosarcoma, malignant rhabdoid tumor of the liver, undifferentiated embryonal sarcoma of the liver, biliary tract rhabdomyosarcoma, and the unique variant of neuroblastoma IVS. Some note should be given about fibrolamellar carcinomas of the liver, which are tumors of adolescence with a predilection for the left liver and have a tendency to be challenging to resect (2-6).

\section{HEPATOCELLULAR CARCINOMA}

HCC is the second most common primary liver malignancy in a pediatric setting (27\%) following HBL. Vascular tumors and sarcomas constitute the remaining $(1,7)$. HCC is becoming a common indication for liver transplantation in childhood with an incidence rate of 0.3 to 0.45 individuals per million per year (23\%). HCC is diagnosed more commonly in adolescents (10-14 years) but has been described in children age 5 and younger. Male children have a greater predisposition to HCC (3:1). HCC typically presents at a more advanced stage in children than in adults. Overall, only $0.5-1 \%$ of all HCCs occur in childhood. HCC has a broad etiologic spectrum including alcoholic cirrhosis, hepatitis B virus (HBV) infection, hepatitis $\mathrm{C}$ virus (HCV) infection and ingestion of aflatoxins from Aspergillus flavum in contaminated food, but these factors show a geographic variation. HCC is most common in central Africa (sub-Saharan regions) and southeast Asia, with an incidence rate of up to 1 per 1,000 , most commonly as a result of HBV infection. HCC remains a common diagnosis in areas with high endemic HBV infection rates. There are rates of up to $100 \%$ positivity for HBV infection in Taiwan, and 64\% positivity for HBV infection in Hong Kong SAR (Special Administrative Region of the People's Republic of China) $(8,9)$. The integration of the HBV genome into the neoplasm genome can be detected by immunohistochemistry and demonstrated at the molecular level, but this event is not necessarily oncogenic; alone it does not result in liver carcinogenesis. A secondary 
promoter (for example, environmental influences or genetic variations) is required for the development of HCC. In several countries, vaccination of neonates has led to a drop in HCC rate in childhood and adulthood.

Numerous genetic abnormalities are associated with HBV-HCC in adults, such as mutations in the cytotoxic T-lymphocyte antigen 4 (CTLA-4) gene, deletion or chromosomal loss of DLC1 (Deleted in Liver Cancer 1) or loss of heterozygosity on the KIFlb promoter region of the Mini-Chromosome Maintenance protein-7 (MCM7) gene and enhancer II (EnhII) $(1,10,11)$. Moreover, alterations of the basal core promoter (BCP) and precore regions of HBV have been found. It has been shown that Pre-S mutations (C1653T, T1753V, and A1762T/G1764A) are explicitly associated with an amplified risk of $\operatorname{HCC}(11,12)$. HCV infection is rarer than HBV infection in children and so is less significant etiologically (13). Other non-viral conditions associated with HCC include glycogen storage diseases type 1, 3, and 4 (poor metabolic control, size and number of adenoma, malignant transformation in adenoma), congenital portosystemic shunts (complete absence of portal vein or type la, presence of nodular regenerative hyperplasia, adenoma, and dysplasia), hepatic venous outflow tract obstruction/Budd-Chiari syndrome (long-standing obstruction, presence of nodular regenerative hyperplasia, inferior caval vein (IVC) obstruction, Factor V Leiden mutation (14), acute intermittent porphyria, porphyria cutanea tarda, hyper-citrullinemia, tyrosinemia (non-usage of [2-(2-nitro-4-trifluoromethyl-benzoyl)-1,3-cyclohexanedione (Nitisinone, NTBC) or late introduction of NTBC), familial intrahepatic cholestasis (BSEP deficiency, TJP2 mutations, MDR3 deficiency), alpha-1-antitrypsin deficiency (AATD), biliary atresia, Alagille syndrome, autoimmune hepatitis, Wilson's disease, and genetic hemochromatosis (1). Genetic syndromes predisposing to HCC include ataxia telangiectasia, Fanconi anemia, familial adenomatous polyposis, and neurofibromatosis. Non-metabolic conditions are presented in the following section. Metabolic diseases are discussed separately.

\section{Biliary atresia}

Biliary atresia (BA) is characterized by a necro-inflammatory process with destructive cholangitis $(15,16)$. The prevalence rate of HCC in BA is $1.3 \%$ (five out of 387 patients) with all but one patient below five years of age. This figure is particularly alarming in the West where rates of BA are up to 30\%, although it has been argued that the said figure may be confounded by surveillance bias (1).

\section{Congenital portosystemic shunts}

Congenital portosystemic shunts (CPSS) are another predisposing factor for liver oncogenesis. CPSS causes nodular transformation in the pediatric liver. Of all types of CPSS, patent ductus venosus, portal vein to IVC, or left portal venous system to IVC are the most common (17-23). Liver tumors have been observed in both extra- (35\%) and intra-hepatic (13\%) types at a median age of eight years; however, the malignant tumors (HBL, HCC, and sarcoma) are exclusively seen alongside the extrahepatic variety. HCC occurs in $2.5 \%$ of patients with CPSS (24). In the case of benign tumors like focal nodular hyperplasia (FNH) and hepatic adenoma, shunt occlusion leads to a decrease in the size of the 
tumor masses, but resection and shunt occlusion, as well as OLT, are necessary for malignant tumors (20).

\section{Budd-Chiari syndrome}

Budd-Chiari syndrome (BCS) is characterized by abdominal pain, ascites, and liver enlargement caused by blockage of the hepatic veins that drain the liver. BCS can be primary (75\%) (polycythemia rubra vera, pregnancy, postpartum state, use of oral contraceptives, paroxysmal nocturnal hemoglobinuria, and lupus anticoagulants) or secondary (25\%) (compression of the hepatic vein by an outside structure [for example, a neoplasm]). HCC is a known sequela of BCS in adults, with a 5-year cumulative incidence of 4\% (1). Nodular regenerative hyperplasia is more commonly associated with the onset of BCS, and is more often associated with male gender, FVL mutation, and inferior vena cava (IVC) obstruction, but can also be seen in tuberculosis, congenital venous webs, and IVC stenosis $(25,26)$.

\section{Alagille syndrome}

Alagille is a multisystem genetic disorder characterized by interlobular bile ductal paucity and chronic hepatocellular cholestasis (27). Alagille syndrome is a result of mutations on one of the two genes: JAG-1 in 90\% of cases, and NOTCH2 in about $1 \%$ of cases. Liver carcinogenesis in Alagille syndrome has been occasionally reported (28-32). In the first two decades of life, patients can develop HCC in conjunction with Alagille syndrome and cirrhosis (32). Upregulation of Notch2 in hepatocytes results in proliferation of hepatocyte and biliary epithelial cells; it also triggers diethylnitrosamine induced HCC formation in mice (33). Neoplastic cells commonly lose contact inhibition to undergo anchorage-independent proliferation. They become resistant to programmed cell death by inactivating the Hippo signaling pathway. It results in activation of the transcriptional co-activator yes-associated protein (YAP). The transcriptional regulator YAP upregulates JAGGED-1 and activates NOTCH pathways in mouse models and humans with HCC and colorectal and pancreatic carcinomas (34). YAP is a transcriptional coactivator and is responsible for the rapid proliferation of neoplastic cells becoming apoptosis-resistant.

\section{Autoimmune hepatitis}

Autoimmune hepatitis (AIH) is a non-metabolic disorder that predisposes to HCC (35). The risk of HCC in adults with AIH is 3.06 per 1,000. Absolute risk of HCC as a sequela of AIH is slightly lower than the risk of HCC attributable to other causes of cirrhosis in adults like hepatitis B, C, or primary biliary cholangitis (PBC) (36). The risk of HCC is related to the extent of cirrhosis at the time of clinical diagnosis of AIH $(\mathrm{OR}=4.08)$. Abnormal liver enzymes (transaminases) are seen on final observation $(\mathrm{OR}=3.66)(36,37)$. Although the incidence of HCC in children is rare, AIH remains a common pediatric liver condition. Non-alcoholic fatty liver disease (NAFLD), type 2 diabetes mellitus, genetic hemochromatosis, and porphyria (acute intermittent and porphyria cutanea tarda) carry a high risk 
of development of HCC in adults, but not in children (38). About 33-50\% of all HCC cases in childhood are sporadic (1).

\section{Symptoms}

Symptoms of HCC in noncirrhotic individuals are similar to those seen in patients harboring other liver tumors. The "tumor quia tumet" or mass-effect includes an abdominal mass, pain, and jaundice. Abnormal liver biochemistry alongside specific clinical signs and symptoms may be present if the tumor originates as a result of liver disease. Clinical signs may include splenomegaly due to portal hypertension and spider nevi, among others. There are no specific findings on full blood count associated with HCC. Liver function tests frequently give abnormal results particularly in children in whom HCC has occurred with frank cirrhosis. Alphafetoprotein (AFP) is increased in 50-70\% of patients with HCC, although it should be kept in mind that persistent elevations of AFP are found in hepatic regeneration. On the other hand, AFP levels greater than 400 to $500 \mathrm{ng} / \mathrm{mL}$ in a patient with liver cirrhosis is strongly suggestive of HCC. HCC should be suspected when AFP levels fall between 200 and $300 \mathrm{ng} / \mathrm{mL}$. AFP has prognostic value and has been used for years as a prognostic (relapse) indicator after chemotherapy. Elevations of the vitamin- $\mathrm{B}_{12}$-binding protein transcobalamin I is a useful indicator for the fibrolamellar variant of HCC or fibrolamellar carcinoma (FLC) (vide infra). Finally, the exclusion of known risk factors, such as HBV/HCV serology, plasma and urine amino acid, urinary succinylacetone for hereditary tyrosinemia, biochemical serum level, and isoelectricfocusing-based phenotype for AAT should be routinely performed. If there is a suspicion of a genetic disease, a genetic confirmation of PFIC 2, hereditary tyrosinemia, and Alagille syndrome should be carried out as soon as possible.

\section{Imaging}

Imaging is useful to determine the site and characteristics of the tumor, to establish the presence of tumor metastases, and to help the surgeon to assess the suitability for prompt resection. HCC is difficult to distinguish from HBL on imagery. Both HCC and HBL are typically large and multifocal. In both tumors, there may be evidence of venous invasion, tissue calcification, and lung metastases. Ultrasound of HCC shows a large, heterogeneous, generally hyperechoic vascular mass. Computed tomography (CT) provides detailed information on the anatomic boundaries of liver tumors, which is essential for the pediatric surgeon. MRI scanning gives information about tumor infiltration into surrounding tissue, enabling precise evaluation of segmental involvement. MRI findings of HCC show a heterogeneous, mostly hypointense neoplasm on T1-weighted images. MRI findings on T2-weighted images of HCC is mildly hyperintense in comparison with healthy liver. Contrast-enhanced T1-weighted images identify a pattern like CT. There is early arterial enhancement and reduced signal intensity in the portal venous phase. Imaging data is essential for clinical staging and surgical intervention. PET scans show areas of high metabolism, which is useful in localizing early metastases or recurrence of the neoplastic disease. In all children without cirrhosis, unless primary surgery is feasible, a biopsy is necessary. Image-guided needle biopsy is 
usually favored to open biopsy due to the multifocal nature of the hepatocellular neoplasm. To avoid tumor seeding in children, the tumor should be approached along a short route through unaffected liver, avoiding Coinaud liver segments that will not be removed at subsequent surgery. Moreover, a coaxial biopsy should be used to obtain several cores of tissue with a single shot. The needle track should be plugged, either with gelatin foam or with a slurry of collagen. HCC in adults has been studied in greater detail than pediatric HCC in terms of cytogenetic and molecular characteristics. Future studies aim to outline molecular pathology of HCC in children (39).

\section{Morphology}

Morphology of adult and pediatric HCC are similar. There are several growth patterns including trabecular (plate-like), solid/compact, pseudoglandular/acinar, and scirrhous (scleroting architectural pattern). Cytologic variants include pleomorphic cells, clear cells, and sarcomatous cells (spindle cells or bizarre giant cells). The cytoplasm of the tumor cells is stained with Hep Par 1, a monoclonal antibody (clone OCH1E5.2.10) in a granular manner, without canalicular or zonal accentuation. The antigen detected by Hep Par 1 appears specifically associated with the mitochondrial membrane of hepatocytes. The use of antigen retrieval (high $\mathrm{pH}$ buffer) and a detection kit which eliminates non-specific biotin reactivity allows the pathologist to use Hep Par 1, which is highly effective on formalinfixed, paraffin embedded tissues. Cautious use of Hep Par 1 antibody in a panel with other positive (AFP, carcinoembryonic antigen with a polyclonal antibody, $\mathrm{CD} 10$ ) as well as negative (epithelial membrane antigen, carcinoembryonic antigen with a monoclonal antibody, CD15) markers of hepatocellular differentiation may assist in accurate diagnosis of hepatocellular carcinoma (Figure 1). Epithelial cell adhesion molecule (EPCAM) expression seems to be far more robust in pediatric than adult $\operatorname{HCC}(7,40)$. In the future, transcriptomics studies may reveal additional data comparing adult and pediatric HCC.

\section{Differential diagnosis}

Distinguishing HBL from HCC may be straightforward in a few cases. HBL may be easily recognized if both epithelial and mesenchymal components are present, but when it shows a macrotrabecular architecture with well-differentiated fetal epithelial cells and no mesenchymal elements, distinction may be practically impossible histologically $(7,41)$. In this scenario, liaison with the clinician is critical. The pathologist should consider that HBL occurs more frequently than HCC in patients aged 5 or younger, very-low-birth-weight infants and premature infants, and with a multiple congenital anomaly syndrome, such as BeckwithWiedemann syndrome. On the other hand, the presence of underlying hepatic disease, especially with a known risk factor, such as hereditary tyrosinemia, favors a diagnosis of HCC over HBL. In the most recent pediatric liver tumor consensus classification, the category of "hepatocellular neoplasm not otherwise specified" has been introduced to acknowledge the challenge of differentiating sporadic cases which show cells that are "transitional" between hepatoblasts and hepatocytes $(39,42)$. 

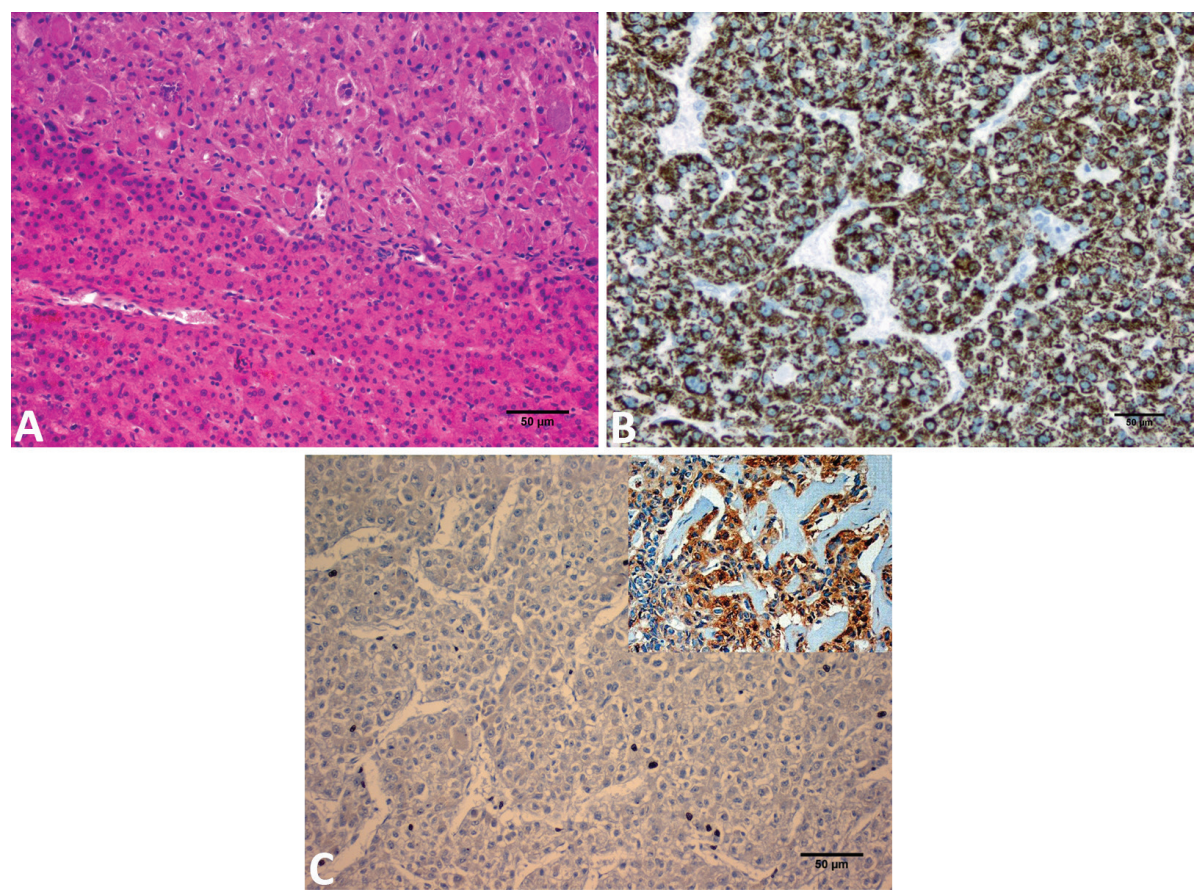

Figure 1. Microphotographs of hepatocellular carcinoma. A. Solid pattern showing large hepatocytes organized in a solid architecture (top of the figure) contrasting with the lobular arrangement of non-tumoral hepatocytes (bottom of the figure) (Hematoxylin-Eosin staining, scale bar: $50 \mu \mathrm{m})$. B. Macrotrabecular pattern of growth showing trabeculae of hepatocytes, which are more than two cells thick. The cytoplasm of the tumor cells is stained with Hep Par 1, which is a monoclonal antibody (clone OCH1E5.2.10) in a granular manner, without canalicular or zonal accentuation. The antigen detected by Hep Par 1 appears to be quite specifically associated with the mitochondrial membrane of hepatocytes. The use of an antigen retrieval (high $\mathrm{pH}$ buffer) and a detection kit which eliminates non-specific biotin reactivity allows the pathologist to use Hep Par 1, which is very effective on formalin-fixed, paraffin embedded tissues. It seems that cautious use of Hep Par 1 antibody in a panel with other positive (alpha fetoprotein, carcinoembryonic antigen with a polyclonal antibody, $\mathrm{CD} 10$ ) as well as negative (epithelial membrane antigen, carcinoembryonic antigen with a monoclonal antibody, CD15) markers of hepatocellular differentiation may assist in the accurate diagnosis of hepatocellular carcinoma (Hep Par 1 immunostaining, Avidin-Biotin Complex, scale bar: $50 \mu \mathrm{m}$ ). C. Macrotrabecular pattern of growth showing trabeculae of hepatocytes, which are more than two cells thick. The cytoplasm of the tumor cells is not stained with FP2 (FP2 immunostaining, Avidin-Biotin-Complex, $50 \mu \mathrm{m}$ ). Mutations in the PKHD1 (polycystic kidney and hepatic disease 1) gene are responsible for all typical forms of autosomal recessive polycystic kidney disease (ARPKD). The PKHD1 gene is associated with a complex splicing pattern and its longest open reading frame product, fibrocystin, also known as polyductin, is a single transmembrane domain glycoprotein. FP2, a fusion protein containing the polyductin intracellular carboxy-terminus has been used to generate a polyclonal antibody that was applied to study the polyductin expression profile in human tissues. The anti-FP2 purified antiserum stains the renal collecting ducts, the thick ascending limbs of Henle in humans and the branching ureteric bud in mouse, the murine intrahepatic and extrahepatic biliary system, and cholangiocarcinoma (inset on the top of the

microphotograph), but not hepatocellular carcinoma making an important negative marker of hepatocellular differentiation. Immunohistochemical detection of polyductin and co-localization with liver progenitor cell markers during normal and abnormal development of the intrahepatic biliary system and in adult hepatobiliary carcinomas. J Cell Mol Med. 2009 Jul;13(7):1279-90). 


\section{Staging}

Staging pediatric liver neoplasms is crucial, but the reality is that there are no uniformly and broadly accepted staging systems for the pediatric HCC (7). In adulthood, the Barcelona Clinic Liver Cancer score is probably the most widely accepted system, because it assesses the state of the tumor, the state of the patient, and the condition of the liver. Use of the tumor node metastasis (TNM) staging system is controversial. TNM does not seem to be well-suited for predicting prognosis in either pediatric HCC or adult HCC (43). Other staging systems include the Cancer of the Liver Italian Program (CLIP) scale and the Okuda system, among others (43).

Once a diagnosis is reached, in the United States of America and Canada, the Children's Oncology Group (COG) provides vital information to children and their families. This support continues throughout treatment and carries on after cure. The COG's adoption of a system based mostly on surgical findings in the late 1980s has been particularly important for the treatment of HCC. In the late 80's, the PRETEXT (PRETreatment EXTent) system was developed by the International Society of Pediatric Oncology (SIOP) Liver Tumor Study (SIOPEL) Group. The PRETEXT was revised in 2005, and again in 2017 (7, 44). This system divides children with liver neoplasms into four categories consistent with the amount of liver segments not involved by the tumor $(7,45)$. A separate classification includes the involvement of the portal and hepatic veins and IVC as well as metastatic disease. The interobserver reliability of the system remains nevertheless quite high. The significant advantage of PRETEXT staging is that it allows stratifying of patients to determine the most effective treatment. Involvement of hepatoduodenal lymph nodes has a role in staging. It is important therefore to take samples from lymph nodes associated with the hepatoduodenal ligament at the time of surgical resection. After resection of the tumor, the 5-year survival rate (5-YSR) ranges between 35 and $50 \%$, while the 5-YRR (5-years recurrence rate) is $20-30 \%(7)$.

\section{Treatment and management}

Traditionally, treatment of malignant liver neoplasm consists of a combination of chemotherapy and surgical resection. The highest cure rates are associated with complete surgical resection with tumor-free resection margins (R1 and R2 equal to zero using the TNM staging). In the case of a child with a liver neoplasm, when a predisposing condition is present, and HCC is likely, primary resection is indicated without biopsy. PRETEXT grade I and II tumors (that is, having 3 or 2 adjacent sectors, respectively, tumor-free) are quite easily removed by surgery, but PRETEXT III tumors (in which only one sector or two nonadjacent sectors are tumor-free) necessitate a surgeon that specializes in liver surgery, and may also require intensive care facilities and liver transplantation teams. PRETEXT IV tumors (in which there are no tumor-free liver segments) are considered unresectable due to extensive liver involvement. Although complete tumor clearance with margins of at least $1 \mathrm{~cm}$ have been considered safe, recent discussion suggests that any clear margin (that is, less than $1 \mathrm{~cm}$ ) may be acceptable. This suggests that all options should be investigated before declaring a tumor nonresectable. Segmental hepatic removal and resection require the application of an intraoperative 
ultrasound examination, which must correlate with the volume of the liver that needs to be removed using CT- or MRI-based calculations (46). In pediatric HCC, the usual limit of resection is calculated by dividing the remnant liver volume (milliliters) by the patient's body weight (kilograms). This value can safely exceed the usual $0.6-0.8 \mathrm{~mL} / \mathrm{kg}$. Orthotopic liver transplantations (OLT) as a treatment for HCC is still controversial, although the criteria for OLT in adults has been modified over time from unrestricted tumor limits to precise tumor burden which meets the conventional Milan criteria (CMC). The CMC-based safe limits for OLT are either a single tumor smaller than $5 \mathrm{~cm}$ in size, or in case of multiple tumors, no more than 3, and each not exceeding $3 \mathrm{~cm}$ in diameter. Satisfying this criterion allows a 5-YSR of about 70\%. Unfortunately, there are no randomized prospective studies comparing liver resection with OLT as treatments for childhood HCC, although we must acknowledge that experience with OLT in pediatric HCC is limited (47). A low 5-YSR has been observed in earlier reports $(48,49)$ with values ranging between 29-35\% in children with unresectable neoplasms. More recent reports from Pittsburgh and other centers show an improvement in 5-YSR rates, with values of up to $60 \%$ (50). Contraindications for OLT include extrahepatic disease and FLC. It has been proposed that decisions on which treatment is most appropriate should be made on a case-by-case basis.

Ablative therapies include radiofrequency ablation and percutaneous ethanol injection (51), although these techniques have been explored mostly for adult HCC. Ablative therapy is comparable to surgery for tumor size equal to $3 \mathrm{~cm}$ or below, but its effect on HCC up to $5 \mathrm{~cm}$ or more is not confirmed to be better than tumor removal. Usefulness of ablative therapy for treatment of HCC of a size greater than $5 \mathrm{~cm}$ seems to be uncertain.

Transfemoral hepatic artery chemoembolization (TACE) is an option for the management of adult HCC with improved 5-YSR in randomized controlled trials (52). TACE indications for pediatric HCC is similar to adult HCC; it may be considered a bridge to OLT or resection with attempted conversion of tumors from nonresectable to resectable. Advantages of TACE include the delivery of high concentrations of cytotoxic drugs to the tumor center, prolonged intratumoral dwell time of drug, and reduced systemic toxicity. TACE appears to be a safe and effective method in children with unresectable hepatocellular neoplasm and is useful for handling hepatic tumor burden, downstaging, and bridging to OLT (53-55). Occasionally, pulmonary embolism and thrombosis of some branches of the hepatic artery have been recorded as severe complications. Despite widespread use of neoadjuvant and adjuvant chemotherapy, there is little evidence to suggest that this translates to a benefit in survival as shown in the North American Intergroup Hepatoma study (INT-0098) and the International and in the Childhood Liver Tumor Study Group (SIOPEL) study $(7,44)$. Nevertheless, adjuvant chemotherapy may be of benefit for children with completely resected HCC. The outcome was uniformly poor for patients with advanced-stage disease. These patients showed a 5-year event-free survival (5-YEFS) with stage III and IV HCC of $23 \%$ and $10 \%$ respectively. The resection of the neoplasm after neoadjuvant chemotherapy was practicable in two patients only. Similarly, the SIOPEL identified a 5 -YEFS of $17 \%$ (1). In the three cooperative studies of the German Society for Pediatric Oncology and Hematology (GPOH), HCC has been targeted with the same regimens as HBL, with surgical resection highly recommended as the primary treatment in all patients $(7,56)$. 
Ifosfamide, a chemotherapy drug used to treat testicular cancer, soft tissue sarcoma, osteogenic sarcoma, urinary bladder cancer, small cell lung cancer, cervical cancer, and ovarian cancer, is given in combination with cisplatin and doxorubicin in a combination termed "IPA". Cisplatin is a chemotherapy drug that interferes with DNA replication using chloride ions to displace water to give the aquo-complex cis- $\left[\mathrm{PtCl}\left(\mathrm{NH}_{3}\right) 2\left(\mathrm{H}_{2} \mathrm{O}\right)\right]^{+}$, while doxorubicin acts to stop growth of cancer cells by blocking topoisomerase 2. IPA was initially present as a chemotherapeutic combination in HB89, but in HB94 carboplatin and etoposide are added to the IPA combination (57). However, the results were not satisfactory, with disease-free survival of only 32\% in HB94. Currently, high-dose carboplatin and etoposide are given for nonresectable HCC. The rationale is to achieve tumor regression to allow for surgical resection. A microscopic residual tumor (termed an Rl resection in relation to TNM classification) may be observed and requires careful histological examination. New targeted therapies for pediatric HCC are being explored and are proving to be promising.

Sorafenib, a multikinase inhibitor that targets vascular endothelial growth factor, in combination with doxorubicin has been demonstrated to be advantageous in advanced adult HCC (58). This study showed improved progression-free survival time and tumor shrinkage. Moreover, GPOH showed that in 50\% (6 of 12) of pediatric patients receiving PLADO (cisplatin/doxorubicin) and sorafenib as first-line therapy for HCC, there was complete remission at a median follow-up of 20 months. Of these six children, four received PLADO/sorafenib and had a liver resection, whereas two children underwent OLT after a localized relapse. Alternate approaches with first- and second-line chemotherapy regimens include gemcitabine/oxaliplatin (GemOx), 5-fluoruracyl (FU)/cisplatin, capecitabine/cisplatin, 5-FU/mitomycin, 5-FU/oxaliplatin, gemcitabine/cisplatin, 5-FU/interferon, and monotherapy with sorafenib $(59,60)$. These approaches are derived from studies on adult patients because pediatric experience is limited. Some chemotherapy protocols have been investigated in pediatrics in small, single-institution trials. They include: (i) the combination of irinotecan, vincristine, temozolomide, and bevacizumab; (ii) the combination of oxaliplatin, irinotecan, and gemcitabine; and (iii) the combination of gemcitabine and oxaliplatin (7). Experience in adult HCC suggests that GemOX is both efficient and well-tolerated in relapsed/refractory neoplastic disease (59).

Knowledge of the biological pathways of liver carcinogenesis has increased in the last decade, generating potential for exploration of new targeted therapies. Erlotinib, which targets the epidermal growth factor (EGF) pathway, may be useful for pediatric HCC (61-64). The mTOR or mammalian target of rapamycin pathway inhibitor everolimus has been demonstrated to have antitumor activity in clinical trials of adult $\operatorname{HCC}(61,65,66)$. cMET, a tyrosine kinase receptor for the hepatocyte growth factor, is implicated in neoplastic formation and proliferation in both HBL and HCC. In a randomized phase 2 study, Tivantinib, a cMET inhibitor, has shown activity in a subset of patients with advanced HCC who had progressed on sorafenib (66-73). Cabozantinib, an inhibitor of c-Met, VEGFR2, AXL and RET, is used to treat medullary thyroid cancer and as a second line treatment for renal cell carcinoma among others. It offers the potential of deactivating multiple mechanisms by which neoplastic cells proliferate (66, $67,74-78)$. 


\section{Treatment-response follow-up}

Repeat CT scans or ultrasonography are useful to observe response to treatment. Imaging can document shrinkage of the liver cancer and chest radiography or CT scans can monitor potential progress of pulmonary metastases. Also, the presence of AFP levels alongside the lack of radiological disease is highly suspicious of minimal residual disease and more sophisticated investigation is mandatory. An increase in AFP levels after initiation of chemotherapy is usually a sensitive marker of treatment failure or relapse. Transcobalamin I has been used as a biomarker of fibrolamellar carcinoma of the liver or fibrolamellar variant of HCC.

Long-term outcomes are dependent on demographics and treatment type. Survival of children aged $0-4$ years is better than that of children aged five years and older, with a 5-YSR of 53\% (unadjusted) compared with 32\% for children aged 5-19 years. Prognosis is better in male children when compared with female children. Some ethnic evaluation studies identified that Asian children have relatively low survival (13\%), compared with white and black children (survival of $33 \%$ and $46 \%$ respectively) (7). On the other hand, results of Surveillance, Epidemiology and End Results (SEER) database are puzzling. A large series of 218 pediatric patients with HCC seem to show no significant difference in the overall survival by age at diagnosis, gender, race/ethnicity, or use of radiation (79-81). Pediatric excisable HCC seems to bear a better prognosis irrespective of histologic subtype. These patients seem to do worse than those with HBL (48). Analysis of post-OLT showed that 1-, 5-, and 10-YSR were $86 \%, 63 \%$, and 58\%, respectively. The primary cause of death of these patients was metastatic or recurrent disease, responsible for $86 \%$ of deaths in children with HCC (49).

\section{HEPATOCELLULAR ADENOMA AND FOCAL NODULAR HYPERPLASIA}

In the differential diagnosis, we should mention hepatocellular adenoma (HCA) and focal nodular hyperplasia (FNH). A large multicenter study resulted in genotype-phenotype classifications of four subtypes of adenomas, including biallelic loss of TCF-1 gene/HNFl $\alpha$ HCA (42\%), WNT pathway mutation/ $\beta$-catenin-activated HCA (12.5\%), inflammatory HCA, and nonmutated/noninflammatory HCA $(82,83)$. The genotype-phenotype HCA classification is paramount because certain genotype-phenotypes are associated with HCC: $7 \%$ in HNFl $\alpha$ mutated adenoma, $13 \%$ in noninflammatory/nonmutated adenomas, and $46 \%$ in $\beta$-catenin-activated HA (83). An inflammatory HCA has the distinctive features of sinusoidal dilatation and perivascular lymphocytic inflammation with immunohistochemical evidence of serum amyloid associated (SAA) protein. Immunohistochemical staining of FNH with glutamine synthetase shows characteristic map-like labeling. FNH is a hyperplastic liver lesion and should be considered a response to a pre-existing arterial malformation (84). Although FNH can occur as multiple lesions in one-fifth of cases, it is usually a solitary hepatic lesion discovered incidentally. FNH is a common tumor lesion, second only to hemangioma and at least ten times more common 
than HCA. Imaging is crucial; ultrasound is highly distinctive in detecting FNH, and both CT scan and MRI are highly reliable techniques in diagnosing FNH (85). Although FNH does not require a liver biopsy for the diagnosis due to good imaging criteria, biopsy may be important if the patient is outside of the typical age range. FNH is a benign lesion with very low risk of rupture and hemorrhage, and is treated with conservative management unless it becomes symptomatic (86).

FNH presents grossly as a well-demarcated non-encapsulated lesion of 4-5 cm in diameter and harboring a central or slightly eccentric scar. Histologically, FNH shows a nodular-shaped architecture with normal hepatic plate architecture and no atypia, fibrous bands radiating from the central or slightly eccentric scar which contain "portal tract-like areas" with bile ductular proliferation, lack of interlobular bile ducts, and thickening of eccentrically located blood vessels. Reticulin stain demonstrates intact reticulin framework which is characteristically lost in malignant hepatic lesions (87). On macroslides, the central scar contains large vessels with fibromuscular hyperplasia, intense lymphocytic infiltrate, and bile duct proliferation, as well as normal hepatocytes with regeneration. Polyclonal carcinoembryonic antigen is useful to reveal a hepatic origin but does not distinguish between benign and malignant tumors. Reticulin histochemical stain plays a major role in pinpointing hepatic adenomas.

Although hepatic adenomas are more common in women of reproductive age, they are not extremely rare in children and adolescents. Hepatic adenomas are usually rare in males and have been associated with oral contraception and anabolic steroid use, but most importantly various metabolic disorders, such as glycogen storage disorder and galactosemia, can exhibit hepatic adenomas, even in childhood. It is rare to see marked elevations in liver enzymes. Genetic analysis can prove neoplastic etiology. Although multiple adenomas can occur, they usually are solitary. There is no liver cirrhosis as background, and differential diagnosis from macro-regenerative nodules is essential. Grossly, hepatic adenomas do not have a capsule, and there is no surrounding fibrosis. Microscopically, hepatocytes are arranged 1 to 3 cell plates thick with a normal appearance. Cytologically, the nucleus to cytoplasmic ratio is normal, but some mild variation in cell size may occur. Atypia is minimal or absent. Mitotic figures are nil or occasionally present, but steatosis, lipofuscin pigment deposition, and Mallory's hyaline can be seen. There are no portal tracts, which are seen in both adenomas and HCCs. A useful feature in distinguishing an adenoma from a well-differentiated HCC is the presence of an intact reticulin framework. The protein FPA can be detected in the serum of children with malignant hepatocellular tumors, but it may not be specific. AFP is absent in adenomas. Similarly, glypican-3, which is a protein encoded by the GPC3 gene that is absent in adenomas and positive in HCCs or dysplastic nodules, although HCCs with negative glypican-3 immunostaining, can be seen. The differential diagnosis with FNH relies on the presence of fibrotic areas with bile ductules and abnormal blood vessels. Liver cirrhosis can help differentiate an adenoma from the large regenerative nodule. Therapy consists of surgical excision. Because of the risk of life-threatening hemorrhage, excisional procedures are strongly indicated for lesions that could not be differentiated on needle biopsy. In the presence of adenomatosis, liver transplantation is essential.

In young patients with a gene mutation predisposing to colorectal carcinoma (for example, TP53 and FAP), colorectal malignancy with metastatic disease can 
occur at an early stage. Metastatic colon cancer needs to be excluded in these patients, and immunohistochemistry may help in this direction. Two antibodies may be beneficial: CDX2 and CK20. CDX2 (Caudal Type Homeobox 2), a gene that directs early embryogenesis in mice, is a marker for gastrointestinal differentiation, especially colorectal differentiation. CK20 or K20, is an antibody for antigen 20 of the keratin intermediate filaments of the cytoskeleton (88). If the tumor is metastatic in origin and arises from the colorectal portion of the gut, both stains should be positive. Also, in the differential diagnosis, a primary cholangiocellular carcinoma must be excluded. The antibodies CK7 and CK19 are appropriate markers for differentiation. Both antibodies are positive in the tissue of a primary cholangiocellular carcinoma (89-91).

As indicated above, three antibodies are useful in highlighting the diagnosis of a primary hepatocellular carcinoma: HepParl, glypican-3, and AFP. The combination of three positive antibodies aids in the diagnosis of HCC. Three antibodies may help in the differential diagnosis with malignant lymphoma: CD45 or common leukocyte antigen, CD3 (T-lymphocyte marker), and CD20 (B-lymphocyte marker). However, immunohistochemistry may not be necessary because cell cytology, tumor growth pattern, and desmoplasia help to exclude a malignant hematological neoplasm. Malignant lymphomas have little cytoplasm and no nested and trabecular growth pattern with a fibrotic stroma. Appropriately, the presence of synaptophysin and chromogranin are useful in identifying a neuroendocrine tumor, considering the nested and trabecular growth pattern can be a classic pattern for neuroendocrine neoplasms.

\section{LIPID-RICH HEPATOCELLULAR CARCINOMA}

The most common histological patterns of HCC are solid, trabecular, pseudoglandular, and scirrhous, with three recognized cytologic variants: pleomorphic, clear cell, and sarcomatoid. In the clear cell variant, cytoplasmic changes are related to glycogen and/or lipid accumulation (lipid-rich HCC, LR-HCC) within the tumor cells. In cytologic samples of low-grade lipid-containing hepatic neoplasms, differentiation of neoplastic cells from benign steatotic cells can be extremely challenging (92-94). Fine-needle aspirates of benign lesions contain rigid cores and large tissue fragments, while LR-HCC shows a breakdown of the reticulin framework (visualized with a routine special stain) with scattered cells and a fine granular-appearing background. LR-HCC is an uncommon HCC variant and needs to be taken into consideration, particularly now that non-alcoholic steatohepatitis and fatty cell change are more common in adolescence and youth (95-98).

\section{FIBROLAMELLAR CARCINOMA}

FLC or fibrolamellar variant of HCC is a rare variant of HCC, and recent investigations have identified a specific molecular signature (99-103). This neoplasm affects adolescents and youth with no significant gender prevalence primarily. FLC chiefly affects Caucasians. Unlike HCC, FLC is never associated with a 
history of parenchymal liver disease. Liver cirrhosis and underlying metabolic disorders are not associated with this tumor. Although broadly considered a variant of HCC, it has been suggested that it ought to be reported as a distinct clinical and histopathologic entity $(41,100)$. FLC accounts for up to almost one-tenth of all HCCs. Moreover, FLC accounts for up to one-third of all pediatric HCCs.

The characteristic histological features of this neoplasm provide the grounds for the singularity of this neoplasm. The Fibrolamellar Carcinoma Consortium is an institutional collaboration involving Memorial Sloan-Kettering Cancer Center (MSKCC), the University of California at San Francisco (UCSF), and Johns Hopkins Hospital. The Consortium was developed to address the challenges associated with investigating FLC, such as small study samples and the lack of awareness of the disease within the oncology community, and with identifying new treatment options. The Consortium presented the pooled demographic, clinical, pathologic, treatment, and survival data of 95 patients with FLC seen at the three institutions from 1986-2011 (104).

\section{Presentation}

Clinically, abdominal pain, hepatomegaly, obstructive jaundice, ascites, systemic manifestations (for example, fever or sense of "fullness"), and rarely gynecomastia and BCS have been observed in patients harboring an FLC (100). Laboratory values that need to be taken into consideration are neurotensin, vitamin $B_{12}$ binding capacity (transcobalamin), and des-gamma-carboxyprothrombin (104). Serum AFP is increased in just 10\% of FLC cases, unlike with HCC where AFP is elevated in $60 \%$ of cases. X-ray imaging shows a central scar which resembles the central scar observed in FNH, a benign lesion with no correlation with FLC. The central scar of FLC is often calcified, which is unusual with FNH.

Grossly, FLC is typically larger than conventional HCC. FLC has an odd propensity to metastasize to regional lymph nodes. Thus, the pediatric surgeon should attempt to sample the regional nodes. FLC generally appears as wellcircumscribed, single white-brown hard mass that shows fibrous bands, similar to FNH. It usually involves the left lobe of the liver, but it has been reported in both lobes.

\section{Pathology}

Microscopically, the tumor is made of large polygonal cells with copious eosinophilic cytoplasm (about 50 microns, that is, approximately double the size of a normal human hepatocyte, which is 20-30 microns) with granular character and large nuclei containing prominent nucleoli. At low magnification, thick fibrous collagen bands are seen transecting the tumor (Figure 2A). They may partially encircle or surround the tumor cells. On histology, pale cytoplasmic bodies (pale bodies) or ground glass cells and PAS-positive hyaline globules and copper depositions are also seen (Figure 2B). Bile is observed using negative Prussian Perl's blue iron stain. In the differential diagnosis of FLC, sclerotic variant of HCC should be mentioned, which rarely harbors the parallel (or almost parallel) running collagen bands. Vascular invasion and necrosis may be seen. Radiological calcification may also be confirmed on histology. 

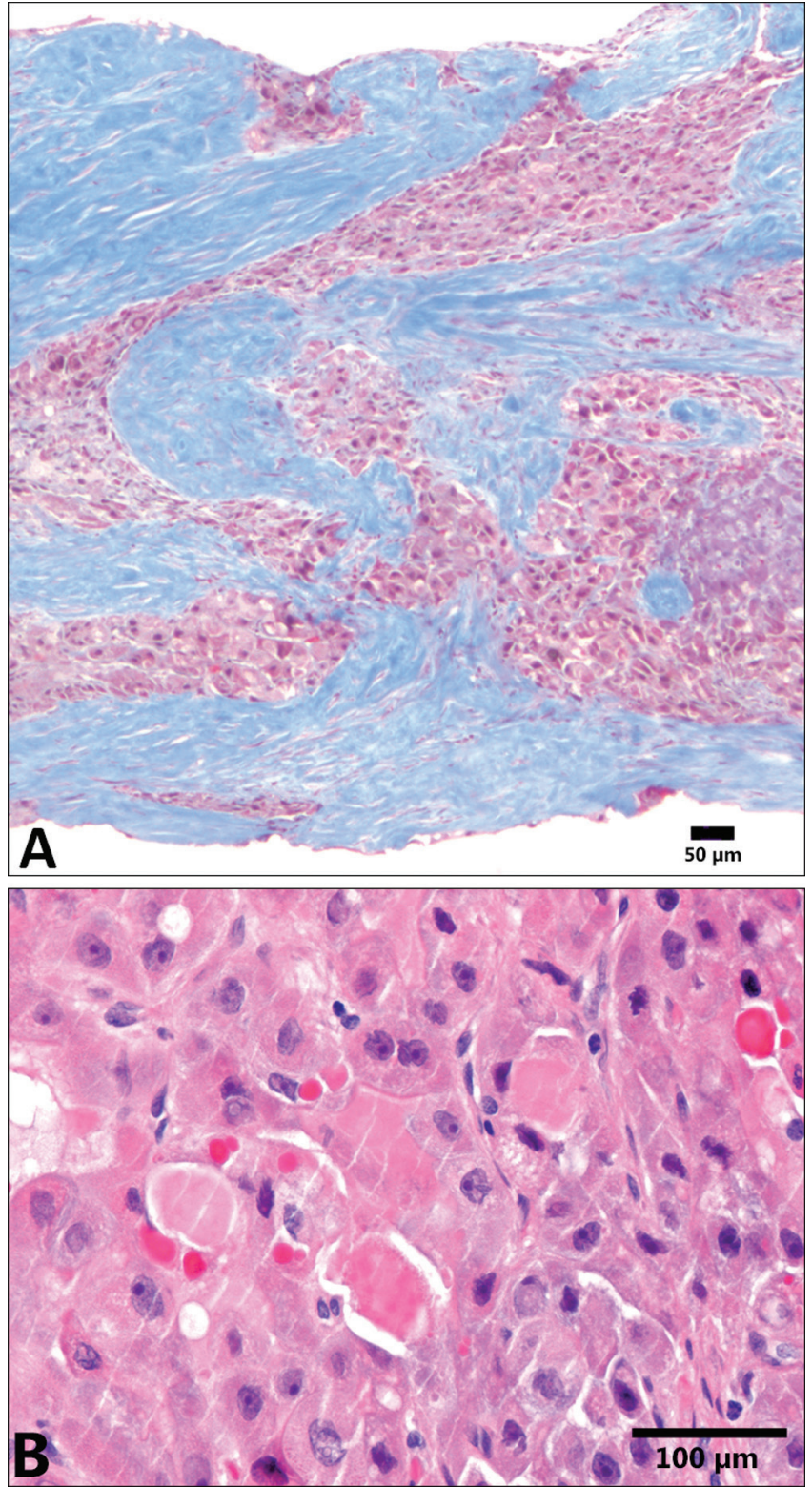

Figure 2. Fibrolamellar carcinoma. A. Tumor tissue showing extensive intratumoral lamellar bands of collagen (blue) separating large polygonal cells (Masson's trichromic stain, scale bar: $50 \mu \mathrm{m})$. B. Tumor tissue showing large polygonal cells with vesiculated nuclei, large nucleoli and intracytoplasmic pale bodies (Hematoxylin and Eosin staining, scale bar: $100 \mu \mathrm{m}$ ). 
A controversial issue is the "mixed" FLC and HCC, but molecular pathology may resolve this dilemma in the future. Additional features that can be encountered are trabecular, adenoid or pelioid patterns that need to be taken into consideration when evaluating needle or open biopsy. Metastases to the regional lymph nodes, peritoneum, and lungs are commonly seen. Immunohistochemistry is an important ancillary tool. FLC shows HepPar-1, keratin 7, epithelial membrane antigen (EMA), CD68 and carcinoembryonic antigen (polyclonal antibody, p-CEA).

Immunohistochemically, there is usually a lack of expression of AFP, synaptophysin, and chromogranin. The p-CEA is shown in a canalicular pattern due to cross-reactivity to biliary glycoprotein I existing in bile canaliculi of healthy liver and HCC. Of note, the monoclonal CEA is usually negative. These findings have suggested to some authors that FLC may be a hybrid neoplasm of hepatobiliary type. FLC may also be positive for antibodies against CAM5.2 (a low molecular weight cytokeratin panel against keratin 7 and keratin 8 present on secretory epithelia but not on stratified squamous epithelia), AEl-3 (a pan-cytokeratin markers grouping low and high molecular weight antibodies), and neurotensin. AAT is usually inconsistently expressed. CK19 is usually negative (105). There may be an expression of epithelial growth factor receptor (EGFR), and human epidermal growth factor receptor (Her-2) (106). Electron microscopy reveals copious mitochondria (107). Pale bodies contain fibrinogen. There is an abundance of rough endoplasmic reticulum (ER) in the neoplastic cells, which may also show dense core neuroendocrine-like granules. However, the neoplastic cells are not positive for neuroendocrine markers by immunohistochemistry (vide supra) or immunogold-marked electron microscopy. Differential diagnoses include sclerosisaccompanied adenosquamous carcinoma, cholangiocellular carcinoma, which is markedly glandular and mucin-positive (108), and FNH. FNH is smaller in size than FLC. FNH contains bile ductular proliferating associated stroma (fibrous) and inflammatory cells. Microscopically, FNH has neither gross bile staining nor hepatocyte atypia. Also, FLC must be differentiated from the sclerosing variant of HCC, which shows no oncocytic change of the neoplastic cells. This tumor is smaller in size than the tumor cells of FLC and shows a typical pseudoglandular pattern. Other differential diagnoses include metastatic carcinoma with sclerotic stroma (a full history is invaluable), neuroendocrine tumors (neuroendocrine markers proof by immunohistochemistry is useful), and paraganglioma, which harbors a Zellballen growth pattern, round/ovoid nuclei without atypia, vascular stroma but no dense fibrosis and is positive for neuroendocrine markers (109). A clear cell variant of FLC has also been described. (110). In addition to classic FLC, the neoplastic clear cells with empty cytoplasm have ballooning and rarefactive changes to their mitochondria (100).

A fusion gene between DNAJB1 and PRKACA characteristically distinguishes FLC from conventional HCC (103). This genetic abnormality is found with loss of genetic material on chromosome 19. It leads to the unusual combination of two genes, DNAJB1 and PRKACA. DNAJB1 is a DnaJ (Hsp40) homolog, subfamily B, member 1 (DNAJB1) or a transcriptional target of forkhead box protein E3 (FOXE3) in a pathway apparently crucial for the development of the eye. PRKACA encodes one of the catalytic subunits of protein kinase A. The "chimeric" gene, which in turn produces an abnormal protein product, is an unusual combination of the two normal proteins. Common pathways that are altered in HCC, 
such as $\beta$-catenin and p53, are not differentially controlled in FLC. Occasionally, there is also an upregulation of other pathways including EGFR, MAPK, PI3K, and RAS (111). In 2015, Riehle et al. highlighted some of these pathways, showing that mTORCl is activated in FLC and has been found in association with fibroblast growth factor receptor 1 (FGFRl) overexpression. This data supports the use of FGFRl inhibitors in patients with FLC (112). Recently, data from the Fibrolamellar Carcinoma Consortium has identified and updated overall survival of FLC (104). About 3/4 of patients with FLC undergo surgical resection and/or OLT and $1 / 3$ receive perioperative therapy. Preoperative chemotherapy, including external beam radiation, and TACE with doxorubicin are the milestones of the perioperative therapy. Chemotherapy agents used in FLC include cisplatin, doxorubicin, fluoropyrimidines, gemcitabine, irinotecan, and oxaliplatin. Postoperative adjuvant chemotherapy and/or radiation should also be considered as relevant options (104).

\section{PEDIATRIC METABOLIC CONDITIONS PREDISPOSING TO HEPATOCELLULAR CARCINOMA}

This section lists metabolic conditions that may predispose to the development of HCC. Liver cirrhosis has been considered a precursor of HCC irrespective of etiology because dysplasia can occur in the setting of a regenerating nodule, but this argument is mainly relevant for adult HCC. In childhood, pediatric metabolic conditions play a major role. About one-third of pediatric cases of HCC are associated with cirrhosis, while liver cirrhosis is present in two-thirds to $90 \%$ of adultonset HCC. The list of pediatric metabolic conditions may be not complete but illustrates most of these conditions. This list includes alpha-1-antitrypsin (AAT) deficiency, hereditary tyrosinemia 1, glycogen storage diseases types I, III, and IV, genetic hemochromatosis, Wilson's disease, acute intermittent porphyria, progressive familial intrahepatic cholestasis type 2, mitochondrial electron transport chain (ETC) disorders, and transaldolase deficiency. However, in some of the above conditions, HCC does not occur at the pediatric age. The most prominent disease in this category of predisposing conditions to HCC is AATD.

\section{Alpha-1-antitrypsin deficiency}

AATD (Laurell-Eriksson-Syndrome) is the result of a gene mutation, commonly found in Caucasians. AAT expression is regulated by the SERPINA1 (SERine Proteinase INhibitor) gene which expresses codominant alleles. The SERPINA1 gene is situated on the protease inhibitor ( $\mathrm{Pi}$ ) locus. It is on the long arm of chromosome 14 (14q31-32). The three most common alleles are the normal M allele, the $\mathrm{S}$ allele and the $\mathrm{Z}$ allele. In the setting of the $\mathrm{S}$ allele, AAT plasma levels are about $60 \%$ of normal, while in the setting of the $\mathrm{Z}$ allele AAT plasma levels are about $10-15 \%(113,114)$. The nomenclature of SERPINA1 alleles is based on isoelectric focusing-determined migration of the protein variants that were identified long before the gene was known. The coding of the alleles was based on migration in gel electrophoresis using the prefix PI (protease inhibitor) serving as 
an alias for the gene (115). The normal AAT protein (the M protein) migrates to the middle of the isoelectric field, while the abnormal AATD protein (the $Z$ variant) migrates slowly. Null alleles are pathogenic alleles that result in either no mRNA product or no protein product. Homozygosity for the $\mathrm{Z}$ mutant allele is accompanied by abnormal retention of altered AAT molecules in the liver, which may lead to neonatal hepatitis, liver disease in children, and liver disease with the development of HCC in young adults (116). AAT is an acute-phase protein with strong inhibitory activity towards proteolytic enzymes, mainly elastase but also trypsin, chymotrypsin, and thrombin. Lack of AAT is also associated with higher risk of chronic obstructive pulmonary disease (COPD), which is characterized clinically by lung emphysema, chronic bronchitis and/or persistent airflow obstruction in young and middle-aged adults, especially smokers. Adult-onset AATD-determined liver disease manifests with fibrosis and cirrhosis. It may occur in the absence of a history of childhood (or neonatal) liver disease. The risk for HCC is increased in individuals with AATD. The hepatocytes are the main source of AAT.

The SERPINA1 gene is closely controlled by different cytokines, including interleukin-1 (IL-1), tumor necrosis factor $\alpha$ (TNF $\alpha$ ), and the interleukin-6 family of cytokines (interleukin-6, leukemia inhibitory factor, oncostatin M). Genetic mutations of SERPINAl cause disturbance in protein structure, resulting in polymerization and intracellular accumulation of the protein. The point mutations accountable for the molecular instability of the protein occur in the axes and sliding regions of the protein. They are located in the areas involved in the movement of the reactive loop (117). These mutations allow for the spontaneous opening of the main $\beta$-pleated sheet of the molecule. It leads to a swift insertion into the sheet of the reactive loop of the subsequent AAT molecule. As a result, loopsheet polymers are formed. Individuals who are either homozygous for most common mutated variant $(-Z)$, or two other rare variants (Siiyama and M-Malton/ M-Cagliari), show protein aggregation $(113,114,118)$. The histological hallmark of liver disease in AATD is the identification of AAT-containing globules which are positive to diastase-resistant PAS-D staining in periportal hepatocytes. The link between AAT and liver malignancy has been explored from several aspects, for example, AAT polymorphisms, elevated serum levels and changes in the content of oligosaccharides of AAT. The impossibility to extrude AAT from the ER leads to the accumulation of polymers in the ER of hepatocytes, leading to damage of the hepatocytes by the gain-of-function mechanism. This mechanism, by which accumulation of protein damages the cell, is crucial. There is evidence from investigations using mice transgenic for the $\mathrm{Z}$ mutant of the human AAT (AAT-Z) gene in which hepatitis, and then HCC, developed (119). Marcus et al. recognized an AAT-Z altered regulation of several genes, including cyclin D1 and MCAM, both of which led to cell proliferation and tumorigenesis (120). Genetically engineered fibroblast cell lines arising from the skin of individuals with PiZZ phenotype with or without liver disease indicate that there is a hold-up in ER degradation of $\mathrm{A}_{1}$ AT-Z (121). The key to liver carcinogenesis seems to reside in inefficient degradation of AlAT-Z in the ER. Variation in the function of mechanisms of intracellular protein degradation and/or variation in the pathways of signal transduction activated to protect the cell from protein mis-localization and/or aggregation seem to result in abnormal cell metabolism of hepatocytes, predisposing to liver carcinogenesis (122). It is known that terminally misfolded proteins are transported in 
a selective manner from the ER into the cytosol. These molecules are subsequently ubiquitinated and degraded by the proteasome in a process called ER-associated degradation (ERAD). Lack of efficient protein degradation or accumulation of misfolded proteins in the ER overwhelms the degradation machinery of the cell, and several ER response pathways are activated. These pathways include the proteasomal degradation pathway and autophagy $(118,123,124)$. While the proteasome is accountable for degrading soluble forms of the $Z$ variant protein (125), autophagy is specific for the removal of insoluble polymers and aggregates. Teckmann et al. found that retention of AAT-Z in the ER is associated with a marked autophagic response $(126,127)$. The diagnosis of AATD relies on the serum concentration of AAT by radial immunodiffusion or nephelometry with molecular genetic confirmation of the variants by screening for the SERPINA1 gene. In conjunction with the periodic pulmonary function tests, children and young adults with AATD and established liver disease should undergo periodic (annually or half-annually) ultrasound examination of the liver to monitor for fibrotic changes and HCC occurrence.

\section{Hereditary tyrosinemia I}

Hereditary tyrosinemia I (HT1, OMIM 276700) is the result of an abnormality of the tyrosine catabolic pathway due to deficiency of the enzyme fumarylacetoacetate hydrolase. It is an autosomal recessive disorder. In the liver, there is an accumulation of toxic metabolites (maleylacetoacetate, fumarylacetoacetate, and succinylacetone) which lead to hepatic and renal manifestations of the disease and carcinogenesis. HCC occurs commonly in HTl, with a prevalence of $14-75 \%$ $(128,129)$. Clinically, the spectrum is widely heterogeneous and includes acute or chronic liver disease, glomerulosclerosis, hypophosphatemic rickets due to renal tubular dysfunction, neurological porphyria-like crisis, hypertrophic cardiomyopathy, hypoglycemia due to hyperinsulinism, and failure to thrive. Currently, treatment of $\mathrm{HTl}$ is inhibition of the formation of toxic metabolites by nitisinone [2-(2-nitro-4-trifluoromethyl-benzoyl)-1,3-cyclohexanedione; NTBC] and the reduction of tyrosine levels by dietary treatment. Heat shock proteins and antiapoptotic proteins have been found to be altered in HTl. Presumably, there is a mechanism whereby transformed cells have a survival advantage in murine models of HTl $(130,131)$. There is a small risk of liver cancer in NTBC treated HTl patients because this compound blocks the enzyme parahydroxyphenyl-pyruvic acid dioxygenase, which is involved in the tyrosine degradation pathway, thus preventing the accumulation of fumarylacetoacetate and succinylacetone. On the other hand, animal models have revealed that NTBC treatment is unsuccessful in normalizing tyrosinemia-induced changes in the expression of transcripts encoding proteins involved in signal transduction, protein turnover, cell growth, and cell proliferation (132). In one study on pediatric patients who underwent OLT, HCC was found in 12 (75\%) liver explants, but in another Iranian study, HCC was present in just 5 (23\%) of the 22 liver explants (133). Screening is recommended in $\mathrm{HTl}$ patients, using regular measures of AFP and imaging. Surveillance typically includes ultrasound, but in the event a suspicious lesion is found, MRI could be used for characterization and staging of lesions, as it is more sensitive compared to ultrasound. 


\section{Progressive familial intrahepatic cholestasis type 2}

Progressive familial intrahepatic cholestasis type 2 (PFIC 2) is associated with a mutation in the $\mathrm{ABCB} 11$ gene, resulting in a deficiency of bile salt export pump (BSEP), a membrane acid transporter of bile canaliculi. PFIC2 represents a specific, previously unrecognized risk for HCC in infants. In BSEP deficiency, there is poor excretion of bile salts through the canalicular membrane, resulting in constant exposure of hepatocytes to bile salts, leading to chronic inflammation and carcinogenesis $(90,91,108,134-142)$. HCC occurs in $5-15 \%$ of pediatric patients with BSEP deficiency, mostly in the second year of life (143-146). It has also been demonstrated that children harboring a D482G mutation have less severe disease and portal hypertension, while HCC occurs most often in children with non-D482G mutations (145). In a European study investigating a cohort of 128 children, single-strand conformation polymorphism (SSCP) analysis and Sanger sequencing of $A B C B 11$ gene identified high risk of HCC (38\% vs. 10\%) in children with the presence of two protein-truncating mutations (146). Interestingly, studies of humans affected by BSEP and Mdr2 knock-out mice revealed that very few somatic mutations accumulate over time in cancer genes, contrary to what occurs in adults with HCC as well as other hepatocellular neoplasms where several mutations progressively accumulate over a period of time. BSEP individuals and animal models show massive gene amplification that affects components of signal transduction pathways. These include the ErbB, activators of c-Jun-N terminal kinases (JNK), the PI3K/Akt and the mitogen-activated protein kinase (MAPK) signaling pathways, among others $(147,148)$. Another study showed that BSEP expression is significantly decreased in HCC patients and is associated with alteration of the nuclear regulatory receptor farsenoid-X receptor (FXR), with an increase in FXR- $\alpha_{1} /$ FXR- $\alpha_{2}$ ratio (149). HCC has also been reported in a new variant of PFIC with marked cholestasis, the so-called TJP2 (tight junction protein 2) deficiency. Protein-truncating mutations in the TJP2 gene result in failure of protein localization and related disruption of tight junction structure leading to severe cholestatic disease of the liver. Claudin (CLDN1) is unable to localize normally to cholangiocyte borders and biliary canaliculus margins, despite normal protein levels. Exposure of canalicular and cholangiocyte membranes to high concentrations of detergent bile acids due to TJP2 deficiency leads to a disintegration of the hepatobiliary structure, with progressive liver injury and malignant transformation $(150,151)$. Lastly, HCC has been sporadically reported in multidrug resistance protein-3 (MDR3) deficiency (PFIC-3), but less frequently than BSEP deficiency (152).

\section{Glycogen storage disorders}

Glycogen storage disorders (GSD) may also be associated with HCC. This neoplasm may develop from adenomas, suggesting that there is an adenomacarcinoma sequence in GSD. GSD Ia, or glucose-6-phosphatase deficiency, may cause HCA in $16-75 \%$ of patients with GSD Ia also harboring HCA. GSD Ia-associated HCA occurs in the second and third decades of life and differs from sporadic HCA in that they are greater in number, involve both the right and left liver, and show no gender predisposition. Good metabolic control influences regression in size and number of HCA in GSD la patients. Malignant conversion 
of HCA to HCC may occur on rare occasions (153-161). In GSD-Ia HCAs, chromosomal peculiarities are present in $60 \%$ of tumors, which is similar to the rate observed in HCA seen in the general population. However, it seems that a simultaneous gain of chromosome $6 \mathrm{p}$ and loss of $6 \mathrm{q}$ are present in GSD-Ia HCA only. Moreover, GSD-Ia HCAs show reduced expression of insulin-like growth factor-2 receptor (IGF2R) and large tumor suppressor kinase-1 (LATS1), which are candidate tumor suppressor genes at $6 \mathrm{q}$ in more than $50 \%$ of the tumors. This data suggests a potential but still inexplicable role of $6 \mathrm{q}$ in oncogenic transformation of such GSD-Ia HCAs (162). Type III GSD (debrancher enzyme deficiency, or Forbes disease, or limit dextrinosis) also presents with HCA, but liver enzymes are increased due to hepatocellular injury, and there is evidence of ballooning cell change and fibrosis. GSD-III HCAs occur in 4-25\% of children. Malignant oncogenic transformation of HCA occurs almost always after liver cirrhosis $(156,163)$. Rarely, HCC can occur in GSD-IV (brancher enzyme deficiency also known as Andersen's disease or amylopectinosis) (164).

\section{Wilson's disease}

Wilson's disease (WD) is characterized by copper accumulation and seems to be protective against tumorigenesis, but HCC has been described (165). A Dutch study targeting 140 adults with WD for over 15 years (166) reported an estimated annual risk of HCC of 9 in 10,000 (0.09\%). However, another multicenter European study of $1,186 \mathrm{WD}$ patients showed a prevalence rate of $0.67 \%(167)$. Other predisposing conditions to HCC include genetic hemochromatosis, acute intermittent porphyria, progressive familial intrahepatic cholestasis type 2, mitochondrial electron transport chain (ETC) disorders, glycogen storage diseases types I, III, and IV, and transaldolase deficiency (168). Transaldolase deficiency is a genetic disease caused by mutations in the transaldolase gene (TALDO1), which leads to abnormally low levels of the transaldolase enzyme. Transaldolase is a metabolic enzyme involved in the pentose phosphate pathway.

\section{CHOLANGIOCELLULAR CARCINOMA}

Cholangiocellular carcinoma (CCA) is very rare in childhood and youth, accounting for less than $1 \%$ of all malignancies in these age groups. CCA arises from the epithelial lining of the bile ducts and harbors a poor prognosis. In a review of the scientific literature and the "Surveillance, Epidemiology, and End Results" (SEER) Program Database, Newsome et al. found 22 individual cases of pediatric CCA published between 1946 and January 2016 (169). Details of these cases can be found in Tables 2 and 3 of the SEER analyses (170-189). Briefly, the patients had a median age of diagnosis of 15 years (range 3-18 years), of which 20 (91\%) had one or more gastrointestinal comorbidities with congenital distortions of the biliary tract and primary sclerosing cholangitis (PSC) being the most prevalent. PSC is a long-term progressive hepatobiliary disease with involvement of the liver, gallbladder, and extrahepatic biliary tract characterized by inflammation and scarring of the bile ducts with potential evolution to liver cirrhosis and liver failure. Abdominal pain, jaundice, and pruritus are the most common clinical signs. In eight patients, 
cancer antigen (CA) 19-9 was reported, and it was increased (>129 U/mL) in four of them (50\%). The SEER database program analysis and the scientific literature evidence showed that after a median follow-up time of 8 months (range 0-60 months), 12 (54.6\%) patients had died, 9 (40.9\%) patients were alive, and $1(4.6 \%)$ had no reported survival data. Most pediatric cases had underlying risk factors for CCA, such as PSC, while in adults only an estimated 30\% of CCAs occurred in patients with an underlying risk factor (108, 190-194). In adults, underlying risk factors include bile duct cysts, primary sclerosing cholangitis (specifically with inflammatory bowel disease), Caroli Disease, and hepatolithiasis. Choledocholithiasis, cholangitis, hepatitis C (HCV), hepatitis B (HBV) and cirrhosis have been considered potential risk factors as well $(108,169)$. There is a potential association of these tumors with viral infections (hepatitis B virus, hepatitis $C$ virus) and alcohol use, which has been seen increasingly when compared with classic textbook associations of liver flukes (Opisthorchis viverrinii and Clonorchis sinensis) and primary sclerosing cholangitis. Other chronic inflammatory processes of the biliary tract have also been associated with CCA. In addition, congenital disorders such as BA and PIFC have been identified as comorbidities. Congenital malformations of the biliary tree, such as choledochal cysts and Caroli disease, may present with obstructive cholestasis; however, patients may be asymptomatic and diagnosed later in life.

\section{Congenital biliary dilatation}

Congenital biliary dilatation (CBD) has been described as an important cause for the development of CCA in younger patients, mostly teenagers, but occasionally in younger children as early 3 years of age (178). The etiology of CCA from $\mathrm{CBD}$ is thought to be the reflux of pancreatic juice into the biliary system duct via a pancreatico-biliary mal-junction (PBMJ). Oncologic transformation can occur in the biliary tree anywhere where the biliary epithelial cells can be influenced by both bile stasis and pancreatic secretion. The first reported malignancy associated with CBD was reported in $1994(195,196)$. The risk of malignant transformation of the biliary epithelium is between 2.5\% and 28\% (193, 194, 197-205). Malignant transformation is accompanied by genetic mutations (206). A preoperative diagnosis of CCA associated with CBD remains difficult to establish and involves identifying either elevated or polypoid lesions in the bile duct. CCA is therefore frequently diagnosed during laparotomy. Once a diagnosis of CBD is made, radical surgery in early-stage disease combined with thorough, intraoperative frozen tissue examination are needed. Adjuvant chemotherapy for tumor-positive surgical margins has been advocated, but remains controversial.

\section{Ductal plate malformation}

Other conditions associated with CCA are ductal plate malformation (DPM)related lesions. An abnormal arrest of the remodeling of the ductal plate during biliary system development is called DPM of the liver (207-216). Polycystic liver disease (PLD) is the representative entity resulting from a DPM, which can be both morphologic mimickers and precursor lesions of neoplastic lesions (217). 
DPM may have several overlapping entities, which are mostly grouped into: (i) Von Meyenburg complexes (VMCs), small nonhereditary nodular cystic lesions; (ii) isolated polycystic liver disease (PCLD); and (iii) autosomal dominant polycystic kidney disease (ADPKD), which shows multiple cysts in both kidney and liver $(218,219)$. An arrest in the development of the intrahepatic biliary system and cystic changes of the bile ducts result from disrupted TGF- $\beta$, Notch, and Wnt signaling or ciliopathy (220). Both PCLD and ADPKD show multiple large cysts replacing normal hepatic parenchyma. Hepatic failure, and complications associated with cysts, such as infection, hemorrhage or rupture, are frequent, but PCLD and ADPKD are not risk factors for CCA in general. VMC is a sporadic, small (diameter less than $0.5 \mathrm{~cm}$ ), usually singular DPM lesion, also called biliary micro-hamartoma. Although it is often an incidental finding in the adult liver, it is rarely encountered in childhood. Multiple VMCs may occur with multiple cysts, which are grossly visible and diffusely located along the biliary tree. Histologically, VMCs consist of irregularly dilated small bile ducts embedded in the fibrous stroma with intraluminal inspissated bile secretion. VMCs are considered a part of the spectrum of adult PCLD, but there is no known genetic background such as ADPKD or PCLD (221). There is a large body of knowledge that VMC has more than a potential role as a preneoplastic lesion for CCA. This knowledge is based on several studies that have reported CCA arising from VMCs, suggesting malignant transformation from VMC to CCA, CCA having histologic similarities with VMC and DPM, and histologic similarity of CCA and VMC in K-ras and p53 mutated animal models inducing CCA (222-232). Most recently, the CCA with DPM pattern seems to have well-defined ARID1A genetic alterations (233).

\section{Pathology and differential diagnosis}

It remains a true challenge for pathologists to distinguish between diffuse-type VMC and CCA. Anatomical locations are used to classify CCA. In the diagnostic routine, we distinguish intrahepatic from extrahepatic CCA. Intrahepatic CCAs arise from the biliary system in the liver (bile ducts and segmental bile ducts), while extrahepatic CCAs arise from perihilar bile ducts (including the right, left and common hepatic ducts) or the extrahepatic bile duct (the common bile duct). Grossly, the tumor may present in the form of a mass or having a periductal infiltrating pattern. Sometimes, the mass-forming and periductal infiltrating patterns are mixed. The mass-forming type of CCA represents the vast majority. Histologically, CCA appears as a moderately differentiated gland, or tubule-shaped atypical cell proliferation on low power and is frequently accompanied by prominent desmoplasia (fibrotic stroma). The stroma is particularly evident at the center of the mass. Unusual growth patterns may also occur, and include trabecular, nested, adenosquamous, squamous, mucinous and signet cell patterns, among others (234). In the trabecular growth pattern, polygonal cells with eosinophilic cytoplasm arranged in thick trabeculae are seen. Immunohistochemical investigation is crucial in most cases to confirm a diagnosis of CCA. CCA are typically positive for keratin 7 (CK7) and keratin 19 (CK19), biliary type of intermediate filaments of the cytoskeleton, carcinoembryonic antigen (CEA), and EMA. Epithelial cells forming bile ducts express CK-7 and CK-19 in addition to CK-8 and CK-18. The latter are also 
present in normal adult hepatocytes. Patients are almost always negative for keratin 20 (CK20) of the intermediate filaments of the cytoskeleton. In our past investigations on liver development (209) and ductal plate malformation of the liver (208, 210), we used three monoclonal antibodies against CK-7 (OV-TL 12/ 30, 1:50, Dako Corporation, Hamburg, Germany), CK-19 (RCK 108, 1:100, Dako Corporation, Hamburg, Germany), and a mixture of cytokeratin epitopes (AE 1/3, 1:2, Linaris, Camon, Wiesbaden, Germany). AE 1 reacts with specific group A acidic keratins with a molecular weight of 40,000-50,000 (CK 10, 14, 15, 16, 19), while AE 3 recognizes all eight group B basic keratins with a molecular weight of 58,000 - 67,000 (CK 1-8). A mixture of monoclonal antibodies AE 1 and AE 3 should theoretically stain both biliary epithelial cells and hepatocytes because AE 1 reacts with CK 19, and AE 3 reacts with both CK 7 and CK 8. However, we found that in formalin-fixed tissue, the AE 113 cocktail reacts only with biliary cells. This is probably due to formaldehyde fixation of the tissue, as previously shown (235-237). The epitope recognized by AE 3 is altered by formalin fixation, making it less available for binding. Furthermore, it differs from other cytokeratin-related epitopes because it can only partially be 'restored' by antigen-unmasking techniques. In CCA, there is no immunohistochemical detection for CDX2 or Caudal Type Homeobox 2, whose gene is a component of the caudal-related homeobox transcription factor family. CDX2 is expressed in the nuclei of intestinal epithelial cells, and diseases associated with CDX2 include Ampulla of Vater adenocarcinoma and mucinous adenocarcinoma of the ovary. Among CDX2 related pathways are transcriptional regulatory networks in embryonic stem cell and incretin synthesis, secretion, and inactivation. Ultrastructurally, CCC tumor cells show cytokeratin filaments, an intracytoplasmic lumen, tight junctions at the apices, and desmosomes at the lateral surfaces of neighboring cells. All these features are characteristics of adenocarcinoma cell origin.

The $8^{\text {th }}$ edition of the Staging Manual of the American Joint Committee on Cancer (AJCC) has different staging systems for intrahepatic, perihilar, distal bile duct, and HCC (238). AJCC staging is based on vascular invasion, number of tumor nodules, perforation of the visceral peritoneum, the involvement of local extrahepatic tissues and the occurrence of periductal infiltration. In the differential diagnoses in childhood and youth, it is rare to see metastatic colorectal carcinoma, although I came across one such case in my practice; the tumor suppressor gene, TP53, was deleted. The major differential diagnosis is with HCC; particularly with unusual growth patterns such as trabecular and nested type, careful consideration is necessary. The lack of nucleoli, the lack of bile production, and the presence of prominent (central) fibrosis is suggestive of CCA. A nested growth pattern would also suggest a neuroendocrine carcinoma, but in this case, I would expect to see granular or "salt-and-pepper" ("stippled") chromatin, although nucleoli can also be seen in NET of high grade. In this setting, the pathologist should consider abundant apoptosis, mitotic figures and tumor necrosis, which may be particularly prominent in neuroendocrine carcinomas. The distinction of CCA from metastatic gall bladder, pancreatic or upper gastrointestinal adenocarcinomas requires clinical correlation, although such tumors are practically non-existent in childhood and youth. Neuroendocrine carcinomas and neuroendocrine tumors are often positive for neuroendocrine 
markers, including chromogranin A and synaptophysin (199, 239). A note should be given to the precursor lesions for CCA, including biliary intraepithelial neoplasia (BilIN I-III) and intraductal papillary mucinous neoplasm of the biliary tract. These two pre-invasive lesions of carcinogenesis of the biliary tract are similar to two precursor lesions of the pancreas: pancreatic intraepithelial neoplasia (PanIN) and intraductal papillary mucinous neoplasm (IPMN) of the pancreas (240).

\section{CONCLUSION}

In regard to hepatocellular lesions, although diagnosis is typically made using diagnostic imaging, anatomical pathology and histology with ancillary studies still play an enormous role in the $21^{\text {st }}$ century. Currently, OLT for unresectable HCC can be curative. Risk factors for recurrence should be considered for HCC only, taking into account factors found in metabolic conditions predisposing to the development of primary neoplasms of the liver. Children and adolescents with underlying metabolic conditions should have a regular follow-up in adulthood. CCA is very rare in pediatrics but is not impossible and must be considered by pediatricians and pediatric pathologists, as well as the risk factors for this tumor.

Acknowledgement: Dr. Sergi's research has been funded by the generosity of the Stollery Children's Hospital Foundation and supporters of the Lois Hole Hospital for Women through the Women and Children's Health Research Institute (WCHRI, Grant ID \#: 2096), Hubei Province Natural Science Funding for Hubei University of Technology (100-Talent Grant for Recruitment Program of Foreign Experts Total Funding: Digital PCR and NGS-based diagnosis for infection and oncology, 2017-2022), Österreichische Krebshilfe Tyrol (Krebsgesellschaft Tirol, Austrian Tyrolean Cancer Research Institute, 2008), Austrian Research Fund (Fonds zur Förderung der wissenschaftlichen Forschung, FWF, Grant ID L313-B13), Canadian Foundation for Women's Health, Cancer Research Society (von Willebrand factor gene expression in cancer cells), Canadian Institutes of Health research (Omega-3 Fatty Acids for Treatment of Intestinal Failure Associated Liver Disease: A Translational Research Study), and the Saudi Cultural Bureau, Ottawa, Canada. The funders had no role in study design, data collection and analysis, decision to publish, or preparation of the manuscript.

Conflict of Interest: The author declares no potential conflicts of interest with respect to research, authorship and/or publication of this article.

Copyright and permission statement: The author confirms that the materials included in this chapter do not violate copyright laws. Where relevant, appropriate permissions have been obtained from the original copyright holder(s). All original sources have been appropriately acknowledged and/or referenced. 


\section{REFERENCES}

1. Khanna R, VermaSK. Pediatric hepatocellular carcinoma. World J Gastroenterol. 2018;24(35):3980-99. https://doi.org/10.3748/wjg.v24.i35.3980

2. Goodman Z, Terracciano L. Tumours and tumour-like lesions of the liver. In: Burt A, Portmann B, Ferrell L, editors. MacSween's pathology of the liver. 5th ed: Churchill Livingstone Elsevier; 2007. p. 765.

3. Ferrell L. Benign and Malignant Tumors of the Liver. In: Odze R, Goldblum J, editors. Surgical Pathology of the GI Tract, Biliary Tract, and Pancreas. Philadelphia, PA: Saunders Elsevier; 2009. https://doi.org/10.1016/B978-141604059-0.50050-3

4. Lopez-Terrada D, Finegold MJ. Tumors of the liver. In: al. SFe, editor. Liver Disease in Children 3rd ed. Cambridge, UK: Cambridge University Press; 2007. p. 943-74. https://doi.org/10.1017/ CBO9780511547409.042

5. Stocker JT, Conran RM, Selby DM. Tumors and pseudotumors of the liver. In: Stocker JT, Askin FB, editors. Pathology of Solid Tumors in Children. New York, NY: Chapman \& Hall; 1998. p. 94-9.

6. Patterson K. Liver Tumors and Tumorlike Masses. In: Parham DM, editor. Pediatic Neoplasia: Morphology and Biology. Philadelphia, PA: Lippincott-Raven; 1996. p. 331-53.

7. Kelly D, Sharif K, Brown RM, Morland B. Hepatocellular carcinoma in children. Clin Liver Dis. 2015;19(2):433-47. https://doi.org/10.1016/j.cld.2015.01.010

8. Chen WJ, Lee JC, Hung WT. Primary malignant tumor of liver in infants and children in Taiwan. J Pediatr Surg. 1988;23(5):457-61. https://doi.org/10.1016/S0022-3468(88)80448-2

9. Chan KL, Fan ST, Tam PK, Chiang AK, Chan GC, Ha SY. Paediatric hepatoblastoma and hepatocellular carcinoma: retrospective study. Hong Kong Med J. 2002;8(1):13-7.

10. Uhl J, Penzel R, Sergi C, Kopitz J, Otto HF, Cantz M. Identification of a CTL4/Neul fusion transcript in a sialidosis patient. FEBS Lett. 2002;521(1-3):19-23. https://doi.org/10.1016/ S0014-5793(02)02748-5

11. Iavarone M, Colombo M. HBV infection and hepatocellular carcinoma. Clin Liver Dis. 2013; 17(3):375-97. https://doi.org/10.1016/j.cld.2013.05.002

12. Liu S, Zhang H, Gu C, Yin J, He Y, Xie J, et al. Associations between hepatitis B virus mutations and the risk of hepatocellular carcinoma: a meta-analysis. J Natl Cancer Inst. 2009;101(15):1066-82. https://doi.org/10.1093/jnci/djp180

13. Granot E, Sokal EM. Hepatitis C Virus in Children: Deferring Treatment in Expectation of DirectActing Antiviral Agents. Isr Med Assoc J. 2015;17(11):707-11.

14. Sergi C, Al Jishi T, Walker M. Factor V Leiden mutation in women with early recurrent pregnancy loss: a meta-analysis and systematic review of the causal association. Arch Gynecol Obstet. 2015;29l(3):671-9. https://doi.org/10.1007/s00404-014-3443-x

15. Hadzic N, Baumann U, McKiernan P, McLin V, Nobili V. Long-term challenges and perspectives of preadolescent liver disease. Lancet Gastroenterol Hepatol. 2017;2(6):435-45. https://doi.org/10.1016/ S2468-1253(16)30160-1

16. Hadzic N, Quaglia A, Portmann B, Paramalingam S, Heaton ND, Rela M, et al. Hepatocellular carcinoma in biliary atresia: King's College Hospital experience. J Pediatr. 2011;159(4):617-22 el. https:// doi.org/10.1016/j.jpeds.2011.03.004

17. De Vito C, Tyraskis A, Davenport M, Thompson R, Heaton N, Quaglia A. Histopathology of livers in patients with congenital portosystemic shunts (Abernethy malformation): a case series of 22 patients. Virchows Arch. 2019;474(1):47-57. https://doi.org/10.1007/s00428-018-2464-4

18. Papamichail M, Pizanias M, Heaton N. Congenital portosystemic venous shunt. Eur J Pediatr. 2018;177(3):285-94. https://doi.org/10.1007/s00431-017-3058-x

19. Blanc T, Guerin F, Franchi-Abella S, Jacquemin E, Pariente D, Soubrane O, et al. Congenital portosystemic shunts in children: a new anatomical classification correlated with surgical strategy. Ann Surg. 2014;260(1):188-98. https://doi.org/10.1097/SLA.0000000000000266

20. Bernard O, Franchi-Abella S, Branchereau S, Pariente D, Gauthier F, Jacquemin E. Congenital portosystemic shunts in children: recognition, evaluation, and management. Semin Liver Dis. 2012; 32(4):273-87. https://doi.org/10.1055/s-0032-1329896 
21. Franchi-Abella S, Branchereau S, Lambert V, Fabre M, Steimberg C, Losay J, et al. Complications of congenital portosystemic shunts in children: therapeutic options and outcomes. J Pediatr Gastroenterol Nutr. 2010;51(3):322-30. https://doi.org/10.1097/MPG.0b013e3181d9cb92

22. Botha JF, Campos BD, Grant WJ, Horslen SP, Sudan DL, Shaw BW Jr, et al. Portosystemic shunts in children: a 15-year experience. J Am Coll Surg. 2004;199(2):179-85. https://doi.org/10.1016/j. jamcollsurg.2004.03.024

23. Murray CP, Yoo SJ, Babyn PS. Congenital extrahepatic portosystemic shunts. Pediatr Radiol. 2003; 33(9):614-20. https://doi.org/10.1007/s00247-003-1002-x

24. Sokollik C, Bandsma RH, Gana JC, van den Heuvel M, Ling SC. Congenital portosystemic shunt: characterization of a multisystem disease. J Pediatr Gastroenterol Nutr. 2013;56(6):675-81. https:// doi.org/10.1097/MPG.0b013e31828b3750

25. Ren W, Qi X, Yang Z, Han G, Fan D. Prevalence and risk factors of hepatocellular carcinoma in BuddChiari syndrome: a systematic review. Eur J Gastroenterol Hepatol. 2013;25(7):830-41. https://doi. org/10.1097/MEG.0b013e32835eb8d4

26. Moucari R, Rautou PE, Cazals-Hatem D, Geara A, Bureau C, Consigny Y, et al. Hepatocellular carcinoma in Budd-Chiari syndrome: characteristics and risk factors. Gut. 2008;57(6):828-35. https://doi. org/10.1136/gut.2007.139477

27. Sergi C, Bahitham W, Al-Bahrani R. Bile Duct Paucity in Infancy. In: Mizuguchi Y, editor. Liver Biopsy in Modern Medicine. London, United Kingdom: IntechOpen; 2011. p. 205-304. https://doi. org/10.5772/25253

28. Beaunoyer M, Vanatta JM, Ogihara M, Strichartz D, Dahl G, Berquist WE, et al. Outcomes of transplantation in children with primary hepatic malignancy. Pediatr Transplant. 2007;11(6):655-60. https://doi.org/10.1111/j.1399-3046.2007.00751.x

29. Kamath BM, Yin W, Miller H, Anand R, Rand EB, Alonso E, et al. Outcomes of liver transplantation for patients with Alagille syndrome: the studies of pediatric liver transplantation experience. Liver Transpl. 2012;18(8):940-8. https://doi.org/10.1002/lt.23437

30. Kamath BM, Baker A, Houwen R, Todorova L, Kerkar N. Systematic Review: The Epidemiology, Natural History, and Burden of Alagille Syndrome. J Pediatr Gastroenterol Nutr. 2018;67(2):148-56. https://doi.org/10.1097/MPG.0000000000001958

31. D'Souza AM, Shah R, Gupta A, Towbin AJ, Alonso M, Nathan JD, et al. Surgical management of children and adolescents with upfront completely resected hepatocellular carcinoma. Pediatr Blood Cancer. 2018;65(11):e27293. https://doi.org/10.1002/pbc.27293

32. Bhadri VA, Stormon MO, Arbuckle S, Lam AH, Gaskin KJ, Shun A. Hepatocellular carcinoma in children with Alagille syndrome. J Pediatr Gastroenterol Nutr. 2005;41(5):676-8. https://doi. org/10.1097/01.mpg.0000179759.60048.c4

33. Dill MT, Tornillo L, Fritzius T, Terracciano L, Semela D, Bettler B, et al. Constitutive Notch2 signaling induces hepatic tumors in mice. Hepatology. 2013;57(4):1607-19. https://doi.org/10.1002/ hep. 26165

34. Tschaharganeh DF, Chen X, Latzko P, Malz M, Gaida MM, Felix K, et al. Yes-associated protein up-regulates Jagged-1 and activates the Notch pathway in human hepatocellular carcinoma. Gastroenterology. 2013;144(7):1530-42 el2. https://doi.org/10.1053/j.gastro.2013.02.009

35. Alam S, Lal BB, Sood V, Rawat D. Pediatric Acute-on-Chronic Liver Failure in a Specialized Liver Unit: Prevalence, Profile, Outcome, and Predictive Factors. J Pediatr Gastroenterol Nutr. 2016;63(4): 400-5. https://doi.org/10.1097/MPG.0000000000001179

36. Tansel A, Katz LH, El-Serag HB, Thrift AP, Parepally M, Shakhatreh MH, et al. Incidence and Determinants of Hepatocellular Carcinoma in Autoimmune Hepatitis: A Systematic Review and Meta-analysis. Clin Gastroenterol Hepatol. 2017;15(8):1207-17 e4. https://doi.org/10.1016/j.cgh. 2017.02.006

37. Hino-Arinaga T, Ide T, Kuromatsu R, Miyajima I, Ogata K, Kuwahara R, et al. Risk factors for hepatocellular carcinoma in Japanese patients with autoimmune hepatitis type 1. J Gastroenterol. 2012;47(5):569-76. https://doi.org/10.1007/s00535-011-0519-2

38. Dragani TA. Risk of HCC: genetic heterogeneity and complex genetics. J Hepatol. 2010;52(2):252-7. https://doi.org/10.1016/j.jhep.2009.11.015 
39. Lopez-Terrada D, Alaggio R, de Davila MT, Czauderna P, Hiyama E, Katzenstein H, et al. Towards an international pediatric liver tumor consensus classification: proceedings of the Los Angeles COG liver tumors symposium. Mod Pathol. 2014;27(3):472-91. https://doi.org/10.1038/modpathol.2013.80

40. Zen Y, Vara R, Portmann B, Hadzic N. Childhood hepatocellular carcinoma: a clinicopathological study of 12 cases with special reference to EpCAM. Histopathology. 2014;64(5):671-82. https://doi. org/10.1111/his. 12312

41. Tanaka Y, Inoue T, Horie H. International pediatric liver cancer pathological classification: current trend. Int J Clin Oncol. 2013;18(6):946-54. https://doi.org/10.1007/s10147-013-0624-8

42. Prokurat A, Kluge P, Kosciesza A, Perek D, Kappeler A, Zimmermann A. Transitional liver cell tumors (TLCT) in older children and adolescents: a novel group of aggressive hepatic tumors expressing betacatenin. Med Pediatr Oncol. 2002;39(5):510-8. https://doi.org/10.1002/mpo.10177

43. Faria SC, Szklaruk J, Kaseb AO, Hassabo HM, Elsayes KM. TNM/Okuda/Barcelona/UNOS/CLIP International Multidisciplinary Classification of Hepatocellular Carcinoma: concepts, perspectives, and radiologic implications. Abdom Imaging. 2014;39(5):1070-87. https://doi.org/10.1007/ s00261-014-0130-0

44. Towbin AJ, Meyers RL, Woodley H, Miyazaki O, Weldon CB, Morland B, et al. 2017 PRETEXT: radiologic staging system for primary hepatic malignancies of childhood revised for the Paediatric Hepatic International Tumour Trial (PHITT). Pediatr Radiol. 2018;48(4):536-54. https://doi.org/10.1007/ s00247-018-4078-z

45. Aronson DC, Schnater JM, Staalman CR, Weverling GJ, Plaschkes J, Perilongo G, et al. Predictive value of the pretreatment extent of disease system in hepatoblastoma: results from the International Society of Pediatric Oncology Liver Tumor Study Group SIOPEL-1 study. J Clin Oncol. 2005;23(6):1245-52. https://doi.org/10.1200/JCO.2005.07.145

46. Silberhumer GR, Steininger R, Laengle F, Muehlbacher F, Zacherl J, Pokieser P. Intraoperative ultrasonography in patients who undergo liver resection or transplantation for hepatocellular carcinoma. Surg Technol Int. 2004;12:145-51.

47. Achilleos OA, Buist LJ, Kelly DA, Raafat F, McMaster P, Mayer AD, et al. Unresectable hepatic tumors in childhood and the role of liver transplantation. J Pediatr Surg. 1996;31(11):1563-7. https://doi. org/10.1016/S0022-3468(96)90179-7

48. Tagge EP, Tagge DU, Reyes J, Tzakis A, Iwatsuki S, Starzl TE, et al. Resection, including transplantation, for hepatoblastoma and hepatocellular carcinoma: impact on survival. J Pediatr Surg. 1992;27(3):292-6; discussion 7. https://doi.org/10.1016/0022-3468(92)90849-3

49. Iwatsuki S, Starzl TE, Sheahan DG, Yokoyama I, Demetris AJ, Todo S, et al. Hepatic resection versus transplantation for hepatocellular carcinoma. Ann Surg. 1991;214(3):221-8; discussion 8-9. https:// doi.org/10.1097/00000658-199109000-00005

50. Reyes JD, Carr B, Dvorchik I, Kocoshis S, Jaffe R, Gerber D, et al. Liver transplantation and chemotherapy for hepatoblastoma and hepatocellular cancer in childhood and adolescence. J Pediatr. 2000;136(6):795-804. https://doi.org/10.1016/S0022-3476(00)44469-0

51. Ikeda H, Hirato J, Suzuki N, Kuroiwa M, Maruyama K, Tsuchida Y. Detection of hepatic oxidative DNA damage in patients with hepatoblastoma and children with non-neoplastic disease. Med Pediatr Oncol. 2001;37(6):505-10. https://doi.org/10.1002/mpo.1243

52. Lo CM, Ngan H, Tso WK, Liu CL, Lam CM, Poon RT, et al. Randomized controlled trial of transarterial lipiodol chemoembolization for unresectable hepatocellular carcinoma. Hepatology. 2002;35(5):1164-71. https://doi.org/10.1053/jhep.2002.33156

53. Li Z, Xiao D, Li X, Zhan P, Wang J, Zhang H. Early recurrence detected in hepatocellular carcinoma patients after transcatheter arterial chemoembolization treatment with plasma cell-free DNA. Eur J Gastroenterol Hepatol. 2019; 31(7):885-92. https://doi.org/10.1097/MEG.0000000000001373

54. Weiss KE, Sze DY, Rangaswami AA, Esquivel CO, Concepcion W, Lebowitz EA, et al. Transarterial chemoembolization in children to treat unresectable hepatocellular carcinoma. Pediatr Transplant. 2018;22(4):e13187. https://doi.org/10.1111/petr.13187

55. Kohorst MA, Warad DM, Matsumoto JM, Heimbach JK, El-Youssef M, Arndt CAS, et al. Management of pediatric hepatocellular carcinoma: A multimodal approach. Pediatr Transplant. 2017;21(6). https://doi.org/10.1111/petr.13007 
56. Hiyama E. Current therapeutic strategies for childhood hepatic malignant tumors. Int J Clin Oncol. 2013;18(6):943-5. https://doi.org/10.1007/s10147-013-0607-9

57. von Schweinitz D, Burger D, Bode U, Weinel P, Erttmann R, Hecker H, et al. [Results of the HB-89 Study in treatment of malignant epithelial liver tumors in childhood and concept of a new HB-94 protocol]. Klin Padiatr. 1994;206(4):282-8. https://doi.org/10.1055/s-2008-1046615

58. Keating GM. Sorafenib: A Review in Hepatocellular Carcinoma. Target Oncol. 2017;12(2):243-53. https://doi.org/10.1007/s11523-017-0484-7

59. Schmid I, von Schweinitz D. Pediatric hepatocellular carcinoma: challenges and solutions. J Hepatocell Carcinoma. 2017;4:15-21. https://doi.org/10.2147/JHC.S94008

60. Schmid I, Haberle B, Albert MH, Corbacioglu S, Frohlich B, Graf N, et al. Sorafenib and cisplatin/doxorubicin (PLADO) in pediatric hepatocellular carcinoma. Pediatr Blood Cancer. 2012;58(4):539-44. https://doi.org/10.1002/pbc.23295

61. Sun W, Cabrera R. Systemic Treatment of Patients with Advanced, Unresectable Hepatocellular Carcinoma: Emergence of Therapies. J Gastrointest Cancer. 2018;49(2):107-15. https://doi.org/ 10.1007/s12029-018-0065-8

62. Kelley RK, Venook AP. Novel therapeutics in hepatocellular carcinoma: how can we make progress? Am Soc Clin Oncol Educ Book. 2013. https://doi.org/10.14694/EdBook_AM.2013.33.e137

63. Finn RS. Emerging targeted strategies in advanced hepatocellular carcinoma. Semin Liver Dis. 2013;33 Suppl 1:S11-9. https://doi.org/10.1055/s-0033-1333632

64. Zhu AX. Systemic treatment of hepatocellular carcinoma: dawn of a new era? Ann Surg Oncol. 2010;17(5):1247-56. https://doi.org/10.1245/s10434-010-0975-6

65. Cholongitas E, Mamou C, Rodriguez-Castro KI, Burra P. Mammalian target of rapamycin inhibitors are associated with lower rates of hepatocellular carcinoma recurrence after liver transplantation: a systematic review. Transpl Int. 2014;27(10):1039-49. https://doi.org/10.1111/tri.12372

66. Waidmann O, Trojan J. Novel drugs in clinical development for hepatocellular carcinoma. Expert Opin Investig Drugs. 2015;24(8):1075-82. https://doi.org/10.1517/13543784.2015.1058776

67. Bouattour M, Raymond E, Qin S, Cheng AL, Stammberger U, Locatelli G, et al. Recent developments of c-Met as a therapeutic target in hepatocellular carcinoma. Hepatology. 2018;67(3):1132-49. https://doi.org/10.1002/hep.29496

68. Gnoni A, Santini D, Scartozzi M, Russo A, Licchetta A, Palmieri V, et al. Hepatocellular carcinoma treatment over sorafenib: epigenetics, microRNAs and microenvironment. Is there a light at the end of the tunnel? Expert Opin Ther Targets. 2015;19(12):1623-35. https://doi.org/10.1517/14728222. 2015.1071354

69. Porta C, Giglione P, Ferrari A, Reversi F, Liguigli W, Imarisio I, et al. Tivantinib (ARQ197) in hepatocellular carcinoma. Expert Rev Anticancer Ther. 2015;15(6):615-22. https://doi.org/10.1586/14737 140.2015 .1050383

70. Qi XS, Guo XZ, Han GH, Li HY, Chen J. MET inhibitors for treatment of advanced hepatocellular carcinoma: A review. World J Gastroenterol. 2015;21(18):5445-53. https://doi.org/10.3748/wjg.v21. i18.5445

71. Rota Caremoli E, Labianca R. Tivantinib: critical review with a focus on hepatocellular carcinoma. Expert Opin Investig Drugs. 2014;23(11):1563-74. https://doi.org/10.1517/13543784.2014.949339

72. Bertino G, Di Carlo I, Ardiri A, Calvagno GS, Demma S, Malaguarnera G, et al. Systemic therapies in hepatocellular carcinoma: present and future. Future Oncol. 2013;9(10):1533-48. https://doi. org/10.2217/fon.13.171

73. Santoro A, Rimassa L, Borbath I, Daniele B, Salvagni S, Van Laethem JL, et al. Tivantinib for secondline treatment of advanced hepatocellular carcinoma: a randomised, placebo-controlled phase 2 study. Lancet Oncol. 2013;14(1):55-63. https://doi.org/10.1016/S1470-2045(12)70490-4

74. Liu PH, Huo TI, Miksad RA. Hepatocellular Carcinoma with Portal Vein Tumor Involvement: Best Management Strategies. Semin Liver Dis. 2018;38(3):242-51. https://doi.org/10.1055/ s-0038-1666805

75. Ikeda M, Morizane C, Ueno M, Okusaka T, Ishii H, Furuse J. Chemotherapy for hepatocellular carcinoma: current status and future perspectives. Jpn J Clin Oncol. 2018;48(2):103-14. https://doi. org/10.1093/jjco/hyx180 
76. Tovoli F, Lorenzo S, Barbera MA, Garajova I, Frega G, Palloni A, et al. Postsorafenib systemic treatments for hepatocellular carcinoma: questions and opportunities after the regorafenib trial. Future Oncol. 2017;13(21):1893-905. https://doi.org/10.2217/fon-2017-0166

77. Brizzi MP, Pignataro D, Tampellini M, Scagliotti GV, Di Maio M. Systemic treatment of hepatocellular carcinoma: why so many failures in the development of new drugs? Expert Rev Anticancer Ther. 2016;16(10):1053-62. https://doi.org/10.1080/14737140.2016.1227706

78. Harding JJ, Abou-Alfa GK. Treating advanced hepatocellular carcinoma: How to get out of first gear. Cancer. 2014;120(20):3122-30. https://doi.org/10.1002/cncr.28850

79. Nautsch F, Ludwig JM, Xing M, Johnson KM, Kim HS. Racial Disparities and Sociodemographic Differences in Incidence and Survival Among Pediatric Patients in the United States With Primary Liver Cancer: A Surveillance, Epidemiology, and End Results (SEER) Population Study. J Clin Gastroenterol. 2018;52(3):262-7. https://doi.org/10.1097/MCG.0000000000000833

80. Lau CS, Mahendraraj K, Chamberlain RS. Hepatocellular Carcinoma in the Pediatric Population: A Population Based Clinical Outcomes Study Involving 257 Patients from the Surveillance, Epidemiology, and End Result (SEER) Database (1973-2011). HPB Surg. 2015;2015:670728. https:// doi.org/10.1155/2015/670728

81. Allan BJ, Wang B, Davis JS, Parikh PP, Perez EA, Neville HL, et al. A review of 218 pediatric cases of hepatocellular carcinoma. J Pediatr Surg. 2014;49(1):166-71. https://doi.org/10.1016/j. jpedsurg.2013.09.050

82. Bioulac-Sage P, Rebouissou S, Thomas C, Blanc JF, Saric J, Sa Cunha A, et al. Hepatocellular adenoma subtype classification using molecular markers and immunohistochemistry. Hepatology. 2007; 46(3):740-8. https://doi.org/10.1002/hep.21743

83. Zucman-Rossi J, Jeannot E, Nhieu JT, Scoazec JY, Guettier C, Rebouissou S, et al. Genotype-phenotype correlation in hepatocellular adenoma: new classification and relationship with HCC. Hepatology. 2006;43(3):515-24. https://doi.org/10.1002/hep.21068

84. Wanless IR, Mawdsley C, Adams R. On the pathogenesis of focal nodular hyperplasia of the liver. Hepatology. 1985;5(6):1194-200. https://doi.org/10.1002/hep.1840050622

85. Mortele KJ, Praet M, Van Vlierberghe H, Kunnen M, Ros PR. CT and MR imaging findings in focal nodular hyperplasia of the liver: radiologic-pathologic correlation. AJR Am J Roentgenol. 2000;175(3):687-92. https://doi.org/10.2214/ajr.175.3.1750687

86. Nahm CB, Ng K, Lockie P, Samra JS, Hugh TJ. Focal nodular hyperplasia--a review of myths and truths. J Gastrointest Surg. 2011;15(12):2275-83. https://doi.org/10.1007/s1 1605-011-1680-x

87. Shafizadeh N, Kakar S. Diagnosis of well-differentiated hepatocellular lesions: role of immunohistochemistry and other ancillary techniques. Adv Anat Pathol. 2011;18(6):438-45. https://doi. org/10.1097/PAP.0b013e318234abb4

88. Liu Q, Teh M, Ito K, Shah N, Ito Y, Yeoh KG. CDX2 expression is progressively decreased in human gastric intestinal metaplasia, dysplasia and cancer. Mod Pathol. 2007;20(12):1286-97. https://doi. org/10.1038/modpathol.3800968

89. Bahitham W, Liao X, Peng F, Bamforth F, Chan A, Mason A, et al. Mitochondriome and cholangiocellular carcinoma. PLoS One. 2014;9(8):e104694. https://doi.org/10.1371/journal.pone.0104694

90. Johnston J, Al-Bahrani R, Abuetabh Y, Chiu B, Forsman CL, Nagamori S, et al. Twisted gastrulation expression in cholangiocellular and hepatocellular carcinoma. J Clin Pathol. 2012;65(10):945-8. https://doi.org/10.1136/jclinpath-2011-200577

91. Dorn L, Menezes LF, Mikuz G, Otto HF, Onuchic LF, Sergi C. Immunohistochemical detection of polyductin and co-localization with liver progenitor cell markers during normal and abnormal development of the intrahepatic biliary system and in adult hepatobiliary carcinomas. J Cell Mol Med. 2009;13(7):1279-90. https://doi.org/10.1111/j.1582-4934.2008.00519.x

92. Yang GC, Yang GY, Tao LC. Distinguishing well-differentiated hepatocellular carcinoma from benign liver by the physical features of fine-needle aspirates. Mod Pathol. 2004;17(7):798-802. https://doi. org/10.1038/modpathol.3800121

93. Yang GC, Yang GY, Tao LC. Cytologic features and histologic correlations of microacinar and microtrabecular types of well-differentiated hepatocellular carcinoma in fine-needle aspiration biopsy. Cancer. 2004;102(1):27-33. https://doi.org/10.1002/cncr.20000 
94. Mitchell CM, Sturgis CD. Lipid-rich hepatocellular carcinoma in fine-needle aspiration biopsy. Diagn Cytopathol. 2009;37(1):36-7. https://doi.org/10.1002/dc.20891

95. Nakagawa H, Hayata Y, Kawamura S, Yamada T, Fujiwara N, Koike K. Lipid Metabolic Reprogramming in Hepatocellular Carcinoma. Cancers (Basel). 2018;10(11):447. https://doi.org/10.3390/ cancers 10110447

96. Yang Y, Shen F, Huang W, Qin S, Huang JT, Sergi C, et al. Glucose Is Involved in the Dynamic Regulation of m6A in Patients With Type 2 Diabetes. J Clin Endocrinol Metab. 2019;104(3):665-73. https://doi.org/10.1210/jc.2018-00619

97. Aspichueta P. Lipid-rich environment: a key role promoting carcinogenesis in obesity-related nonalcoholic fatty liver disease. Gut. 2018;67(8):1376-7. https://doi.org/10.1136/gutjnl-2018-316047

98. Orikasa H, Ohyama R, Tsuka N, Eyden BP, Yamazaki K. Lipid-rich clear-cell hepatocellular carcinoma arising in non-alcoholic steatohepatitis in a patient with diabetes mellitus. J Submicrosc Cytol Pathol. 2001;33(1-2):195-200.

99. Reid LM, Sethupathy P. The DNAJB1-PRKACA chimera: Candidate biomarker and therapeutic target for fibrolamellar carcinomas. Hepatology. 2016;63(2):662-4. https://doi.org/10.1002/hep.28307

100. Sergi CM. Hepatocellular Carcinoma, Fibrolamellar Variant: Diagnostic Pathologic Criteria and Molecular Pathology Update. A Primer. Diagnostics (Basel). 2015;6(1):3. https://doi.org/10.3390/ diagnostics6010003

101. Graham RP, Jin L, Knutson DL, Kloft-Nelson SM, Greipp PT, Waldburger N, et al. DNAJB1-PRKACA is specific for fibrolamellar carcinoma. Mod Pathol. 2015;28(6):822-9. https://doi.org/10.1038/ modpathol.2015.4

102. Xu L, Hazard FK, Zmoos AF, Jahchan N, Chaib H, Garfin PM, et al. Genomic analysis of fibrolamellar hepatocellular carcinoma. Hum Mol Genet. 2015;24(1):50-63. https://doi.org/10.1093/hmg/ddu4l8

103. Honeyman JN, Simon EP, Robine N, Chiaroni-Clarke R, Darcy DG, Lim, II, et al. Detection of a recurrent DNAJB1-PRKACA chimeric transcript in fibrolamellar hepatocellular carcinoma. Science. 2014;343(6174):1010-4. https://doi.org/10.1126/science.1249484

104. Ang CS, Kelley RK, Choti MA, Cosgrove DP, Chou JF, Klimstra D, et al. Clinicopathologic characteristics and survival outcomes of patients with fibrolamellar carcinoma: data from the fibrolamellar carcinoma consortium. Gastrointest Cancer Res. 2013;6(1):3-9.

105. Klein WM, Molmenti EP, Colombani PM, Grover DS, Schwarz KB, Boitnott J, et al. Primary liver carcinoma arising in people younger than 30 years. Am J Clin Pathol. 2005;124(4):512-8. https://doi. org/10.1309/TTOR7KAL32228E99

106. Buckley AF, Burgart LJ, Kakar S. Epidermal growth factor receptor expression and gene copy number in fibrolamellar hepatocellular carcinoma. Hum Pathol. 2006;37(4):410-4. https://doi.org/10.1016/j. humpath.2005.12.009

107. Torbenson M. Review of the clinicopathologic features of fibrolamellar carcinoma. Adv Anat Pathol. 2007;14(3):217-23. https://doi.org/10.1097/PAP.0b013e3180504913

108. Al-Bahrani R, Abuetabh Y, Zeitouni N, Sergi C. Cholangiocarcinoma: risk factors, environmental influences and oncogenesis. Ann Clin Lab Sci. 2013;43(2):195-210.

109. Corti B, D'Errico A, Pierangeli F, Fiorentino M, Altimari A, Grigioni WF. Primary paraganglioma strictly confined to the liver and mimicking hepatocellular carcinoma: an immunohistochemical and in situ hybridization study. Am J Surg Pathol. 2002;26(7):945-9. https://doi.org/10.1097/ 00000478-200207000-00015

110. Cheuk W, Chan JK. Clear cell variant of fibrolamellar carcinoma of the liver. Arch Pathol Lab Med. 2001;125(9):1235-8. https://doi.org/10.5858/2001-125-1235-CCVOFC

111. Kannangai R, Vivekanandan P, Martinez-Murillo F, Choti M, Torbenson M. Fibrolamellar carcinomas show overexpression of genes in the RAS, MAPK, PIK3, and xenobiotic degradation pathways. Hum Pathol. 2007;38(4):639-44. https://doi.org/10.1016/j.humpath.2006.07.019

112. Riehle KJ, Yeh MM, Yu JJ, Kenerson HL, Harris WP, Park JO, et al. mTORCl and FGFRl signaling in fibrolamellar hepatocellular carcinoma. Mod Pathol. 2015;28(1):103-10. https://doi.org/10.1038/ modpathol.2014.78

113. Fabbretti G, Sergi C, Consalez G, Faa G, Brisigotti M, Romeo G, et al. Genetic variants of alpha-l-antitrypsin (AAT). Liver. 1992;12(4 Pt 2):296-301. https://doi.org/10.1111/j.1600-0676.1992.tb01064.x 
114. Sergi C, Consalez GG, Fabbretti G, Brisigotti M, Faa G, Costa V, et al. Immunohistochemical and genetic characterization of the M Cagliari alpha-1-antitrypsin molecule (M-like alpha-1-antitrypsin deficiency). Lab Invest. 1994;70(1):130-3.

115. Spada F, Candiano G, Sergi C, Ghiggeri GM, Callea F, Gusmano R. Purification of alpha-1-antitrypsin monomer by preparative electrophoresis. J Clin Pathol. 1994;47(7):661-3. https://doi.org/10.1136/ jcp.47.7.661

116. Sergi C, Benstz J, Feist D, Nutzenadel W, Otto HF, Hofmann WJ. Bile duct to portal space ratio and ductal plate remnants in liver disease of infants aged less than 1 year. Pathology. 2008;40(3):260-7. https://doi.org/10.1080/00313020801911538

117. Carrell RW, Lomas DA. Alphal-antitrypsin deficiency--a model for conformational diseases. N Engl J Med. 2002;346(1):45-53. https://doi.org/10.1056/NEJMra010772

118. Topic A, Ljujic M, Radojkovic D. Alpha-1-antitrypsin in pathogenesis of hepatocellular carcinoma. Hepat Mon. 2012;12(10 HCC):e7042. https://doi.org/10.5812/hepatmon.7042

119. Carlson JA, Rogers BB, Sifers RN, Finegold MJ, Clift SM, DeMayo FJ, et al. Accumulation of PiZ alpha 1-antitrypsin causes liver damage in transgenic mice. J Clin Invest. 1989;83(4):1183-90. https://doi.org/10.1172/JCI113999

120. Marcus NY, Brunt EM, Blomenkamp K, Ali F, Rudnick DA, Ahmad M, et al. Characteristics of hepatocellular carcinoma in a murine model of alpha-1-antitrypsin deficiency. Hepatol Res. 2010;40(6):641-53. https://doi.org/10.1111/j.1872-034X.2010.00663.x

121. Wu Y, Whitman I, Molmenti E, Moore K, Hippenmeyer P, Perlmutter DH. A lag in intracellular degradation of mutant alpha l-antitrypsin correlates with the liver disease phenotype in homozygous PiZZ alpha 1-antitrypsin deficiency. Proc Natl Acad Sci U S A. 1994;91(19):9014-8. https://doi. org/10.1073/pnas.91.19.9014

122. Hidvegi T, Ewing M, Hale P, Dippold C, Beckett C, Kemp C, et al. An autophagy-enhancing drug promotes degradation of mutant alphal-antitrypsin $\mathrm{Z}$ and reduces hepatic fibrosis. Science. 2010;329(5988):229-32. https://doi.org/10.1126/science.1190354

123. Chiu B, Jantuan E, Shen F, Chiu B, Sergi C. Autophagy-Inflammasome Interplay in Heart Failure: A Systematic Review on Basics, Pathways, and Therapeutic Perspectives. Ann Clin Lab Sci. 2017; 47(3):243-52.

124. Perlmutter DH. Pathogenesis of chronic liver injury and hepatocellular carcinoma in alpha-1-antitrypsin deficiency. Pediatr Res. 2006;60(2):233-8. https://doi.org/10.1203/01.pdr.0000228350.61496.90

125. Qu D, Teckman JH, Omura S, Perlmutter DH. Degradation of a mutant secretory protein, alphal-antitrypsin $\mathrm{Z}$, in the endoplasmic reticulum requires proteasome activity. J Biol Chem. 1996;271(37):22791-5. https://doi.org/10.1074/jbc.271.37.22791

126. Teckman JH, Gilmore R, Perlmutter DH. Role of ubiquitin in proteasomal degradation of mutant alpha(1)-antitrypsin Z in the endoplasmic reticulum. Am J Physiol Gastrointest Liver Physiol. 2000;278(1):G39-48. https://doi.org/10.1152/ajpgi.2000.278.1.G39

127. Teckman JH, An JK, Loethen S, Perlmutter DH. Fasting in alphal-antitrypsin deficient liver: constitutive [correction of consultative] activation of autophagy. Am J Physiol Gastrointest Liver Physiol. 2002;283(5):G1156-65. https://doi.org/10.1152/ajpgi.00041.2002

128. Mayorandan S, Meyer U, Gokcay G, Segarra NG, de Baulny HO, van Spronsen F, et al. Cross-sectional study of 168 patients with hepatorenal tyrosinaemia and implications for clinical practice. Orphanet J Rare Dis. 2014;9:107. https://doi.org/10.1186/s13023-014-0107-7

129. Zeybek AC, Kiykim E, Soyucen E, Cansever S, Altay S, Zubarioglu T, et al. Hereditary tyrosinemia type 1 in Turkey: twenty year single-center experience. Pediatr Int. 2015;57(2):281-9. https://doi. org/10.1111/ped.12503

130. Bergeron A, Jorquera R, Orejuela D, Tanguay RM. Involvement of endoplasmic reticulum stress in hereditary tyrosinemia type I. J Biol Chem. 2006;281(9):5329-34. https://doi.org/10.1074/jbc. M506804200

131. Vogel A, van Den Berg IE, Al-Dhalimy M, Groopman J, Ou CN, Ryabinina O, et al. Chronic liver disease in murine hereditary tyrosinemia type 1 induces resistance to cell death. Hepatology. 2004;39(2):433-43. https://doi.org/10.1002/hep.20077 
132. Luijerink MC, Jacobs SM, van Beurden EA, Koornneef LP, Klomp LW, Berger R, et al. Extensive changes in liver gene expression induced by hereditary tyrosinemia type I are not normalized by treatment with 2-(2-nitro-4-trifluoromethylbenzoyl)-1,3-cyclohexanedione (NTBC). J Hepatol. 2003; 39(6):901-9. https://doi.org/10.1016/S0168-8278(03)00433-1

133. Bahador A, Dehghani SM, Geramizadeh B, Nikeghbalian S, Bahador M, Malekhosseini SA, et al. Liver Transplant for Children With Hepatocellular Carcinoma and Hereditary Tyrosinemia Type 1. Exp Clin Transplant. 2015;13(4):329-32.

134. Al-Bahrani R, Tuertcher D, Zailaie S, Abuetabh Y, Nagamori S, Zetouni N, et al. Differential SIRT1 expression in hepatocellular carcinomas and cholangiocarcinoma of the liver. Ann Clin Lab Sci. 2015;45(1):3-9.

135. Wu Y, Ren F, Chai Y, Xue Z, Shen C, Zhang X, et al. Prognostic value of inflammation-based indexes for intrahepatic cholangiocarcinoma following curative resection. Oncol Lett. 2019;17(1):165-74.

136. Seo S, Yoh T, Morino K, Fuji H, Taura K, Fukumitsu K, et al. The Relationship Between (18)F-FDG Uptake on PET/CT and Markers of Systemic Inflammatory Response in Patients Undergoing Surgery for Intrahepatic Cholangiocarcinoma. Anticancer Res. 2019;39(1):341-6. https://doi.org/10.21873/ anticanres. 13117

137. Nakagawa H, Suzuki N, Koike K. Mouse Model for Cholangiocarcinoma from Peribiliary Glands. Methods Mol Biol. 2019;1905:237-45. https://doi.org/10.1007/978-1-4939-8961-4_21

138. Sripa B, Tangkawattana S, Brindley PJ. Update on Pathogenesis of Opisthorchiasis and Cholangiocarcinoma. Adv Parasitol. 2018;102:97-113. https://doi.org/10.1016/bs.apar.2018.10.001

139. Edwards SW, Spofford EM, Price C, Wright HL, Salao K, Suttiprapa S, et al. Opisthorchiasis-Induced Cholangiocarcinoma: How Innate Immunity May Cause Cancer. Adv Parasitol. 2018;101:149-76. https://doi.org/10.1016/bs.apar.2018.05.006

140. Taghavi SA, Eshraghian A, Niknam R, Sivandzadeh GR, Bagheri Lankarani K. Diagnosis of cholangiocarcinoma in primary sclerosing cholangitis. Expert Rev Gastroenterol Hepatol. 2018;12(6):575-84. https://doi.org/10.1080/17474124.2018.1473761

141. Chung BK, Karlsen TH, Folseraas T. Cholangiocytes in the pathogenesis of primary sclerosing cholangitis and development of cholangiocarcinoma. Biochim Biophys Acta Mol Basis Dis. 2018; 1864(4 Pt B):1390-400. https://doi.org/10.1016/j.bbadis.2017.08.020

142. Surapaitoon A, Suttiprapa S, Mairiang E, Khuntikeo N, Pairojkul C, Bethony J, et al. Subsets of Inflammatory Cytokine Gene Polymorphisms are Associated with Risk of Carcinogenic Liver Fluke Opisthorchis viverrini-Associated Advanced Periductal Fibrosis and Cholangiocarcinoma. Korean J Parasitol. 2017;55(3):295-304. https://doi.org/10.3347/kjp.2017.55.3.295

143. Knisely AS, Strautnieks SS, Meier Y, Stieger B, Byrne JA, Portmann BC, et al. Hepatocellular carcinoma in ten children under five years of age with bile salt export pump deficiency. Hepatology. 2006;44(2):478-86. https://doi.org/10.1002/hep.21287

144. Davit-Spraul A, Fabre M, Branchereau S, Baussan C, Gonzales E, Stieger B, et al. ATP8B1 and ABCB11 analysis in 62 children with normal gamma-glutamyl transferase progressive familial intrahepatic cholestasis (PFIC): phenotypic differences between PFIC1 and PFIC2 and natural history. Hepatology. 2010;51(5):1645-55. https://doi.org/10.1002/hep.23539

145. Pawlikowska L, Strautnieks S, Jankowska I, Czubkowski P, Emerick K, Antoniou A, et al. Differences in presentation and progression between severe FICl and BSEP deficiencies. J Hepatol. 2010;53(1): 170-8. https://doi.org/10.1016/j.jhep.2010.01.034

146. Strautnieks SS, Byrne JA, Pawlikowska L, Cebecauerova D, Rayner A, Dutton L, et al. Severe bile salt export pump deficiency: 82 different ABCB11 mutations in 109 families. Gastroenterology. 2008;134(4):1203-14. https://doi.org/10.1053/j.gastro.2008.01.038

147. Iannelli F, Collino A, Sinha S, Radaelli E, Nicoli P, D’Antiga L, et al. Corrigendum: Massive gene amplification drives paediatric hepatocellular carcinoma caused by bile salt export pump deficiency. Nat Commun. 2015;6:7456. https://doi.org/10.1038/ncomms8456

148. Iannelli F, Collino A, Sinha S, Radaelli E, Nicoli P, D’Antiga L, et al. Massive gene amplification drives paediatric hepatocellular carcinoma caused by bile salt export pump deficiency. Nat Commun. 2014;5:3850. https://doi.org/10.1038/ncomms4850 
149. Chen Y, Song X, Valanejad L, Vasilenko A, More V, Qiu X, et al. Bile salt export pump is dysregulated with altered farnesoid $\mathrm{X}$ receptor isoform expression in patients with hepatocellular carcinoma. Hepatology. 2013;57(4):1530-41. https://doi.org/10.1002/hep.26187

150. Zhou S, Hertel PM, Finegold MJ, Wang L, Kerkar N, Wang J, et al. Hepatocellular carcinoma associated with tight-junction protein 2 deficiency. Hepatology. 2015;62(6):1914-6. https://doi.org/10.1002/ hep. 27872

151. Sambrotta M, Strautnieks S, Papouli E, Rushton P, Clark BE, Parry DA, et al. Mutations in TJP2 cause progressive cholestatic liver disease. Nat Genet. 2014;46(4):326-8. https://doi.org/10.1038/ ng. 2918

152. Vij M, Shanmugam NP, Reddy MS, Govil S, Rela M. Hepatocarcinogenesis in multidrug-resistant P-glycoprotein 3 deficiency. Pediatr Transplant. 2017;21(3). https://doi.org/10.1111/petr.12889

153. Reddy SK, Austin SL, Spencer-Manzon M, Koeberl DD, Clary BM, Desai DM, et al. Liver transplantation for glycogen storage disease type Ia. J Hepatol. 2009;51(3):483-90. https://doi.org/10.1016/j. jhep.2009.05.026

154. Sentner CP, Hoogeveen IJ, Weinstein DA, Santer R, Murphy E, McKiernan PJ, et al. Glycogen storage disease type III: diagnosis, genotype, management, clinical course and outcome. J Inherit Metab Dis. 2016;39(5):697-704. https://doi.org/10.1007/s10545-016-9932-2

155. Kishnani PS, Austin SL, Abdenur JE, Arn P, Bali DS, Boney A, et al. Diagnosis and management of glycogen storage disease type I: a practice guideline of the American College of Medical Genetics and Genomics. Genet Med. 2014;16(11):el. https://doi.org/10.1038/gim.2014.128

156. Kishnani PS, Austin SL, Arn P, Bali DS, Boney A, Case LE, et al. Glycogen storage disease type III diagnosis and management guidelines. Genet Med. 2010;12(7):446-63. https://doi.org/10.1097/ GIM.0b013e3181e655b6

157. Franco LM, Krishnamurthy V, Bali D, Weinstein DA, Arn P, Clary B, et al. Hepatocellular carcinoma in glycogen storage disease type Ia: a case series. J Inherit Metab Dis. 2005;28(2):153-62. https://doi. org/10.1007/s10545-005-7500-2

158. Rake JP, Visser G, Labrune P, Leonard JV, Ullrich K, Smit GP. Glycogen storage disease type I: diagnosis, management, clinical course and outcome. Results of the European Study on Glycogen Storage Disease Type I (ESGSD I). Eur J Pediatr. 2002;161 Suppl 1:S20-34. https://doi.org/10.1007/ BF02679990

159. Bianchi L. Glycogen storage disease I and hepatocellular tumours. Eur J Pediatr. 1993;152 Suppl 1:S63-70. https://doi.org/10.1007/BF02072092

160. Labrune P, Trioche P, Duvaltier I, Chevalier P, Odievre M. Hepatocellular adenomas in glycogen storage disease type I and III: a series of 43 patients and review of the literature. J Pediatr Gastroenterol Nutr. 1997;24(3):276-9. https://doi.org/10.1097/00005176-199703000-00008

161. Oterdoom LH, Verweij KE, Biermann K, Langeveld M, van Buuren HR. Hepatocellular Adenomas and Carcinoma in Asymptomatic, Non-Cirrhotic Type III Glycogen Storage Disease. J Gastrointestin Liver Dis. 2015;24(4):515-8. https://doi.org/10.15403/jgld.2014.1121.244.had

162. Kishnani PS, Chuang TP, Bali D, Koeberl D, Austin S, Weinstein DA, et al. Chromosomal and genetic alterations in human hepatocellular adenomas associated with type Ia glycogen storage disease. Hum Mol Genet. 2009;18(24):4781-90. https://doi.org/10.1093/hmg/ddp441

163. Demo E, Frush D, Gottfried M, Koepke J, Boney A, Bali D, et al. Glycogen storage disease type III-hepatocellular carcinoma a long-term complication? J Hepatol. 2007;46(3):492-8. https://doi. org/10.1016/j.jhep.2006.09.022

164. Romano F, Stroppa P, Bravi M, Casotti V, Lucianetti A, Guizzetti M, et al. Favorable outcome of primary liver transplantation in children with cirrhosis and hepatocellular carcinoma. Pediatr Transplant. 2011;15(6):573-9. https://doi.org/10.1111/j.1399-3046.2011.01528.x

165. Rosencrantz RA, LeCompte L, Yusuf Y. Beneath the Copper-Pediatric Wilson's Disease Cirrhosis and Hepatocellular Carcinoma: A Case Report with Literature Review. Semin Liver Dis. 2015;35(4): 434-8. https://doi.org/10.1055/s-0035-1567828

166. van Meer S, de Man RA, van den Berg AP, Houwen RH, Linn FH, van Oijen MG, et al. No increased risk of hepatocellular carcinoma in cirrhosis due to Wilson disease during long-term follow-up. J Gastroenterol Hepatol. 2015;30(3):535-9. https://doi.org/10.1111/jgh.12716 
167. Pfeiffenberger J, Mogler C, Gotthardt DN, Schulze-Bergkamen H, Litwin T, Reuner U, et al. Hepatobiliary malignancies in Wilson disease. Liver Int. 2015;35(5):1615-22. https://doi.org/10.1111/liv.12727

168. Sergi C, Jundt K, Seipp S, Goeser T, Theilmann L, Otto G, et al. The distribution of HBV, HCV and HGV among livers with fulminant hepatic failure of different aetiology. J Hepatol. 1998;29(6):861-71. https://doi.org/10.1016/S0168-8278(98)80112-8

169. Newsome JR, Venkatramani R, Heczey A, Danysh HE, Fishman DS, Miloh T. Cholangiocarcinoma Among Children and Adolescents: A Review of the Literature and Surveillance, Epidemiology, and End Results Program Database Analysis. J Pediatr Gastroenterol Nutr. 2018;66(1):e12-e8. https://doi. org/10.1097/MPG.0000000000001749

170. Armanino LP. Idiopathic dilation of the common bile duct with coexistent primary hepatic carcinoma: report of a case. Ann Intern Med. 1946;24:714-26. https://doi.org/10.7326/0003-4819-24-4-714

171. Fujiwara Y, Ohizumi T, Kakizaki G, Ishidate T. A case of congenital choledochal cyst associated with carcinoma. J Pediatr Surg. 1976;11(4):587-8. https://doi.org/10.1016/S0022-3468(76)80021-8

172. Kulkarni PB, Beatty E Jr. Cholangiocarcinoma associated with biliary cirrhosis due to congenital biliary atresia. Am J Dis Child. 1977;131(4):442-4. https://doi.org/10.1001/archpedi. 1977.02120170068013

173. Iwai N, Deguchi E, Yanagihara J, Iwai M, Matsuo H, Todo S, et al. Cancer arising in a choledochal cyst in a 12-year-old girl. J Pediatr Surg. 1990;25(12):1261-3. https://doi.org/10.1016/ 0022-3468(90)90525-E

174. Tanaka S, Kubota M, Yagi M, Okuyama N, Ohtaki M, Yamazaki S, et al. An 11-year-old male patient demonstrating cholangiocarcinoma associated with congenital biliary dilatation. J Pediatr Surg. 2006;41(1):e15-9. https://doi.org/10.1016/j.jpedsurg.2005.10.066

175. Scheimann AO, Strautnieks SS, Knisely AS, Byrne JA, Thompson RJ, Finegold MJ. Mutations in bile salt export pump (ABCB11) in two children with progressive familial intrahepatic cholestasis and cholangiocarcinoma. J Pediatr. 2007;150(5):556-9. https://doi.org/10.1016/j.jpeds.2007.02.030

176. Mangeya N, Mafukidze AT, Pascoe M, Mbuwayesango B, Madziva D, Ndlovu N, et al. Cholangiocarcinoma presenting in an adolescent with vertically acquired HIV infection. Int J STD AIDS. 2008;19(10):717-8. https://doi.org/10.1258/ijsa.2008.008078

177. Nakamura H, Katayose Y, Rikiyama T, Onogawa T, Yamamoto K, Yoshida H, et al. Advanced bile duct carcinoma in a 15-year-old patient with pancreaticobiliary maljunction and congenital biliary cystic disease. J Hepatobiliary Pancreat Surg. 2008;15(5):554-9. https://doi.org/10.1007/ s00534-007-1310-x

178. Saikusa N, Naito S, Iinuma Y, Ohtani T, Yokoyama N, Nitta K. Invasive cholangiocarcinoma identified in congenital biliary dilatation in a 3-year-old boy. J Pediatr Surg. 2009;44(11):2202-5. https://doi. org/10.1016/j.jpedsurg.2009.06.037

179. Channabasappa N, Johnson-Welch S, Mittal N. De novo cholangiocarcinoma after liver transplantation in a pediatric patient. Pediatr Transplant. 2010;14(8):E110-4. https://doi.org/10.1111/ j.1399-3046.2009.01220.x

180. Deneau M, Adler DG, Schwartz JJ, Hutson W, Sorensen J, Book L, et al. Cholangiocarcinoma in a 17 -year-old boy with primary sclerosing cholangitis and inflammatory bowel disease. J Pediatr Gastroenterol Nutr. 2011;52(5):617-20. https://doi.org/10.1097/MPG.0b013e3181f9a5d2

181. Huddleston BJ, Lamb RD, Gopez EV, Adler DG, Collins BT. Cholangiocarcinoma in a 17-year-old boy with primary sclerosing cholangitis and UroVysion fluorescent in situ hybridization. Diagn Cytopathol. 2012;40(4):337-41. https://doi.org/10.1002/dc.21629

182. Vera A, Villaveces D, Lopez R. Orthotopic liver transplantation for biliary atresia complicated by incidental cholangiocarcinoma. J Pediatr Gastroenterol Nutr. 2012;55(3):336-7. https://doi.org/ 10.1097/MPG.0b013e318233ff17

183. Lai J, Taouli B, Iyer KR, Arnon R, Thung SN, Magid MS, et al. Cholangiolocellular carcinoma in a pediatric patient with small duct sclerosing cholangitis: a case report. Semin Liver Dis. 2012;32(4):360-6. https://doi.org/10.1055/s-0032-1329904

184. Deneau M, Jensen MK, Holmen J, Williams MS, Book LS, Guthery SL. Primary sclerosing cholangitis, autoimmune hepatitis, and overlap in Utah children: epidemiology and natural history. Hepatology. 2013;58(4):1392-400. https://doi.org/10.1002/hep.26454 
185. Peneau A, Savoye G, Turck D, Dauchet L, Fumery M, Salleron J, et al. Mortality and cancer in pediatric-onset inflammatory bowel disease: a population-based study. Am J Gastroenterol. 2013;108(10):1647-53. https://doi.org/10.1038/ajg.2013.242

186. Liu R, Cox K, Guthery SL, Book L, Witt B, Chadwick B, et al. Cholangiocarcinoma and high-grade dysplasia in young patients with primary sclerosing cholangitis. Dig Dis Sci. 2014;59(9):2320-4. https://doi.org/10.1007/s10620-014-3152-0

187. Yoon HJ, Jeon TY, Yoo SY, Kim JH, Eo H, Lee SK, et al. Hepatic tumours in children with biliary atresia: single-centre experience in 13 cases and review of the literature. Clin Radiol. 2014;69(3):e113-9. https://doi.org/10.1016/j.crad.2013.10.017

188. Hall C, Mamlok V, Al-Khalil I. A Sporadic Case of Advanced Metastatic Cholangiocarcinoma in a Child: A Case Report and Review of Literature. J Pediatr Hematol Oncol. 2015;37(5):e333-5. https:// doi.org/10.1097/MPH.0000000000000335

189. Izumi H, Yazawa N, Furukawa D, Masuoka Y, Yamada M, Mashiko T, et al. Bile duct carcinoma associated with congenital biliary dilatation in a 16-year-old female: a case report and literature review. Surg Case Rep. 2016;2(1):5. https://doi.org/10.1186/s40792-016-0132-y

190. Tyson GL, El-Serag HB. Risk factors for cholangiocarcinoma. Hepatology. 2011;54(1):173-84. https:// doi.org/10.1002/hep.24351

191. Adenugba A, Khan SA, Taylor-Robinson SD, Cox IJ, Toledano MB, Thillainayagam AV, et al. Polychlorinated biphenyls in bile of patients with biliary tract cancer. Chemosphere. 2009;76(6):841-6. https://doi.org/10.1016/j.chemosphere.2009.04.003

192. Burak K, Angulo P, Pasha TM, Egan K, Petz J, Lindor KD. Incidence and risk factors for cholangiocarcinoma in primary sclerosing cholangitis. Am J Gastroenterol. 2004;99(3):523-6. https://doi. org/10.1111/j.1572-0241.2004.04067.x

193. Boberg KM, Bergquist A, Mitchell S, Pares A, Rosina F, Broome U, et al. Cholangiocarcinoma in primary sclerosing cholangitis: risk factors and clinical presentation. Scand J Gastroenterol. 2002;37(10):1205-11. https://doi.org/10.1080/003655202760373434

194. Khan SA, Davidson BR, Goldin RD, Heaton N, Karani J, Pereira SP, et al. Guidelines for the diagnosis and treatment of cholangiocarcinoma: an update. Gut. 2012;61(12):1657-69. https://doi. org/10.1136/gutjnl-2011-301748

195. Irwin ST, Morison JE. Congenital cyst of common bile-duct containing stones and undergoing cancerous change. Br J Surg. 1944;32:319-21. https://doi.org/10.1002/bjs.18003212614

196. Ferraris LV, Navarro A, Malbran JE. Dilatation congéniata del hepato-colédoco y adenocarcinoma. Bol Soc Cirug Cordoba. 1944;5:21.

197. Chapman RW. Risk factors for biliary tract carcinogenesis. Ann Oncol. 1999;10 Suppl 4:308-11. https://doi.org/10.1093/annonc/10.suppl_4.S308

198. Blechacz B. Cholangiocarcinoma: Current Knowledge and New Developments. Gut Liver. 2017;11(1):13-26. https://doi.org/10.5009/gnl15568

199. Blechacz B, Komuta M, Roskams T, Gores GJ. Clinical diagnosis and staging of cholangiocarcinoma. Nat Rev Gastroenterol Hepatol. 2011;8(9):512-22. https://doi.org/10.1038/nrgastro.2011.131

200. Blechacz BR, Gores GJ. Cholangiocarcinoma. Clin Liver Dis. 2008;12(1):131-50, ix. https://doi. org/10.1016/j.cld.2007.11.003

201. Todani T, Watanabe Y, Toki A, Morotomi Y. Classification of congenital biliary cystic disease: special reference to type Ic and IVA cysts with primary ductal stricture. J Hepatobiliary Pancreat Surg. 2003;10(5):340-4. https://doi.org/10.1007/s00534-002-0733-7

202. Todani T, Watanabe Y, Narusue M, Tabuchi K, Okajima K. Congenital bile duct cysts: Classification, operative procedures, and review of thirty-seven cases including cancer arising from choledochal cyst. Am J Surg. 1977;134(2):263-9. https://doi.org/10.1016/0002-9610(77)90359-2

203. Bloustein PA. Association of carcinoma with congenital cystic conditions of the liver and bile ducts. Am J Gastroenterol. 1977;67(1):40-6.

204. Nagorney DM, McIlrath DC, Adson MA. Choledochal cysts in adults: clinical management. Surgery. 1984;96(4):656-63.

205. Rossi RL, Silverman ML, Braasch JW, Munson JL, ReMine SG. Carcinomas arising in cystic conditions of the bile ducts. A clinical and pathologic study. Ann Surg. 1987;205(4):377-84. https://doi. org/10.1097/00000658-198704000-00006 
206. Masuhara S, Kasuya K, Aoki T, Yoshimatsu A, Tsuchida A, Koyanagi Y. Relation between K-ras codon 12 mutation and p53 protein overexpression in gallbladder cancer and biliary ductal epithelia in patients with pancreaticobiliary maljunction. J Hepatobiliary Pancreat Surg. 2000;7(2):198-205. https://doi.org/10.1007/s005340050176

207. Callea F, Sergi C, Fabbretti G, Brisigotti M, Cozzutto C, Medicina D. Precancerous lesions of the biliary tree. J Surg Oncol Suppl. 1993;3:131-3. https://doi.org/10.1002/jso.2930530535

208. Sergi C, Adam S, Kahl P, Otto HF. Study of the malformation of ductal plate of the liver in Meckel syndrome and review of other syndromes presenting with this anomaly. Pediatr Dev Pathol. 2000;3(6):568-83. https://doi.org/10.1007/s100240010104

209. Sergi C, Adam S, Kahl P, Otto HF. The remodeling of the primitive human biliary system. Early Hum Dev. 2000;58(3):167-78. https://doi.org/10.1016/S0378-3782(00)00065-7

210. Sergi C, Kahl P, Otto HF. Contribution of apoptosis and apoptosis-related proteins to the malformation of the primitive intrahepatic biliary system in Meckel syndrome. Am J Pathol. 2000;156(5):1589-98. https://doi.org/10.1016/S0002-9440(10)65031-6

211. Desmet VJ. Congenital diseases of intrahepatic bile ducts: variations on the theme "ductal plate malformation”. Hepatology. 1992;16(4):1069-83. https://doi.org/10.1002/hep.1840160434

212. Desmet VJ. What is congenital hepatic fibrosis? Histopathology. 1992;20(6):465-77. https://doi. org/10.1111/j.1365-2559.1992.tb01031.x

213. Desmet VJ. Ductal plates in hepatic ductular reactions. Hypothesis and implications. III. Implications for liver pathology. Virchows Arch. 2011;458(3):271-9. https://doi.org/10.1007/s00428-011-1050-9

214. Roskams T, Desmet V. Embryology of extra- and intrahepatic bile ducts, the ductal plate. Anat Rec (Hoboken). 2008;291(6):628-35. https://doi.org/10.1002/ar.20710

215. Van Eyken P, Sciot R, Callea F, Van der Steen K, Moerman P, Desmet VJ. The development of the intrahepatic bile ducts in man: a keratin-immunohistochemical study. Hepatology. 1988;8(6):1586-95. https://doi.org/10.1002/hep. 1840080619

216. Hammar JA. Uber die erste Entstehung der nicht kapillaren intrahepatischen Gallengange beim Menschen. Z Mikrosk Anat Forsch. 1926;5:59-89.

217. Lee KB. Histopathology of a benign bile duct lesion in the liver: Morphologic mimicker or precursor of intrahepatic cholangiocarcinoma. Clin Mol Hepatol. 2016;22(3):400-5. https://doi.org/10.3350/ cmh.2016.0105

218. Zheng W, Shen F, Hu R, Roy B, Yang J, Wang Q, et al. Far Upstream Element-Binding Protein 1 Binds the 3' Untranslated Region of PKD2 and Suppresses Its Translation. J Am Soc Nephrol. 2016;27(9):2645-57. https://doi.org/10.1681/ASN.2015070836

219. Johnson CA, Gissen P, Sergi C. Molecular pathology and genetics of congenital hepatorenal fibrocystic syndromes. J Med Genet. 2003;40(5):311-9. https://doi.org/10.1136/jmg.40.5.311

220. Wills ES, Roepman R, Drenth JP. Polycystic liver disease: ductal plate malformation and the primary cilium. Trends Mol Med. 2014;20(5):261-70. https://doi.org/10.1016/j.molmed.2014.01.003

221. Kida T, Nakanuma Y, Terada T. Cystic dilatation of peribiliary glands in livers with adult polycystic disease and livers with solitary nonparasitic cysts: an autopsy study. Hepatology. 1992;16(2):334-40. https://doi.org/10.1002/hep.1840160209

222. Sugawara T, Shindoh J, Hoshi D, Hashimoto M. Intrahepatic cholangiocarcinoma and portal hypertension developing in a patient with multicystic biliary microhamartomas. Malays J Pathol. 2018;40(3):331-5.

223. Lendvai G, Szekerczes T, Illyes I, Dora R, Kontsek E, Gogl A, et al. Cholangiocarcinoma: Classification, Histopathology and Molecular Carcinogenesis. Pathol Oncol Res. 2018. https://doi.org/10.1007/ s12253-018-0491-8

224. Bhalla A, Mann SA, Chen S, Cummings OW, Lin J. Histopathological evidence of neoplastic progression of von Meyenburg complex to intrahepatic cholangiocarcinoma. Hum Pathol. 2017;67:217-24. https://doi.org/10.1016/j.humpath.2017.08.004

225. Tsokos CG, Krings G, Yilmaz F, Ferrell LD, Gill RM. Proliferative index facilitates distinction between benign biliary lesions and intrahepatic cholangiocarcinoma. Hum Pathol. 2016;57:61-7. https://doi. org/10.1016/j.humpath.2016.06.019

226. Ettel M, Eze O, Xu R. Clinical and biological significance of precursor lesions of intrahepatic cholangiocarcinoma. World J Hepatol. 2015;7(25):2563-70. https://doi.org/10.4254/wjh.v7.i25.2563 
227. Nakanuma Y, Tsutsui A, Ren XS, Harada K, Sato Y, Sasaki M. What are the precursor and early lesions of peripheral intrahepatic cholangiocarcinoma? Int J Hepatol. 2014;2014:805973. https://doi. org/10.1155/2014/805973

228. Kim HK, Jin SY. Cholangiocarcinoma arising in von Meyenburg complexes. Korean J Hepatol. 2011;17(2):161-4. https://doi.org/10.3350/kjhep.2011.17.2.161

229. Jain D, Nayak NC, Saigal S. Hepatocellular carcinoma arising in association with von-Meyenburg's complexes: an incidental finding or precursor lesions? A clinicopatholigic study of 4 cases. Ann Diagn Pathol. 2010;14(5):317-20. https://doi.org/10.1016/j.anndiagpath.2010.04.003

230. Heinke T, Pellacani LB, Costa Hde O, Fuziy RA, Franco M. Hepatocellular carcinoma in association with bile duct hamartomas: report on 2 cases and review of the literature. Ann Diagn Pathol. 2008;12(3):208-11. https://doi.org/10.1016/j.anndiagpath.2006.12.003

231. Jain D, Sarode VR, Abdul-Karim FW, Homer R, Robert ME. Evidence for the neoplastic transformation of Von-Meyenburg complexes. Am J Surg Pathol. 2000;24(8):1131-9. https://doi.org/ 10.1097/00000478-200008000-00011

232. Blanc JF, Bernard PH, Carles J, Le Bail B, Balabaud C, Bioulac-Sage P. Cholangiocarcinoma arising in Von Meyenburg complex associated with hepatocellular carcinoma in genetic haemochromatosis. Eur J Gastroenterol Hepatol. 2000;12(2):233-7. https://doi.org/10.1097/00042737-200012020-00016

233. Sasaki M, Sato Y, Nakanuma Y. Cholangiolocellular Carcinoma With "Ductal Plate Malformation" Pattern May Be Characterized by ARIDlA Genetic Alterations. Am J Surg Pathol. 2019;43(3):352-60. https://doi.org/10.1097/PAS.0000000000001201

234. Nakanuma Y, Kakuda Y. Pathologic classification of cholangiocarcinoma: New concepts. Best Pract Res Clin Gastroenterol. 2015;29(2):277-93. https://doi.org/10.1016/j.bpg.2015.02.006

235. Cooper D, Schermer A, Sun TT. Classification of human epithelia and their neoplasms using monoclonal antibodies to keratins: strategies, applications, and limitations. Lab Invest. 1985;52(3):243-56.

236. Sun TT, Tseng SC, Huang AJ, Cooper D, Schermer A, Lynch MH, et al. Monoclonal antibody studies of mammalian epithelial keratins: a review. Ann N Y Acad Sci. 1985;455:307-29. https://doi.org/ 10.1111/j.1749-6632.1985.tb50419.x

237. Treem WR, Krzymowski GA, Cartun RW, Pedersen CA, Hyams JS, Berman M. Cytokeratin immunohistochemical examination of liver biopsies in infants with Alagille syndrome and biliary atresia. J Pediatr Gastroenterol Nutr. 1992;15(1):73-80. https://doi.org/10.1097/00005176-199207000-00011

238. AJCC. AJCC Cancer Staging Manual. 8 ed. New York: Springer; 2016.

239. Sempoux C, Jibara G, Ward SC, Fan C, Qin L, Roayaie S, et al. Intrahepatic cholangiocarcinoma: new insights in pathology. Semin Liver Dis. 2011;31(1):49-60. https://doi.org/10.1055/s-0031-1272839

240. Nakanuma Y, Sasaki M, Sato Y, Ren X, Ikeda H, Harada K. Multistep carcinogenesis of perihilar cholangiocarcinoma arising in the intrahepatic large bile ducts. World J Hepatol. 2009;1(1):35-42. https://doi.org/10.4254/wjh.v1.i1.35 